\title{
AN INVESTIGATION OF JEWISH ETHNIC IDENTITY AND IDENTIFICATION AND THEIR PSYCHOLOGICAL CORRELATES FOR AMERICAN JEWS
}

\section{DISSERTATION}

\author{
Presented in Partial Fulfillment of the Requirements for \\ The Degree Doctor of Philosophy in the \\ Graduate School of The Ohio State University
}
by
Regina Kakhnovets, M. A.
$* * * * *$
The Ohio State University
2005

Dissertation Committee:

Dr. Don M. Dell, Adviser

Approved by

Dr. Richard Russell

Dr. Karen Taylor

Adviser

Graduate Program in Psychology 


\begin{abstract}
The nature of Jewish identity was investigated in this study. It was suggested that Jewish identity is an ethnic identity, which is different from Jewish identification. It was also suggested that Jewish ethnic identity is related to measures of well-being and religiosity and spirituality. The instruments of this study included the Multigroup Ethnic Identity Measure, the Collective Self-Esteem Scale, the Rosenberg Self Esteem Scale, the National Jewish Population Survey Identification Scale, the Global Spirituality Assessment Inventory, the Religious Orientation Scale, and the Center for Epidemiological Studies Depression Scale, and a demographic questionnaire. Two samples of participants completed these measures on the internet. The first sample consisted of college students recruited from the Research Experience Program at The Ohio State University. The second sample was recruited from various organizations in the community.
\end{abstract}

The findings of this study indicate that Jewish identity is an ethnic identity. Jewish ethnic identity was positively correlated with Jewish Identification, lower rates of 
depression, higher self-esteem, and higher rates of satisfaction with life. Jewish ethnic identity was also found to be related to measures of religiosity and spirituality, and this relationship was moderated by Jewish identification. 
This work is dedicated to my family, and especially my parents Zakhar and Bronia

Kakhnovets. Their love inspires me every day. Without their sacrifices, this work would have never been possible. 


\section{ACKNOWLEDGMENTS}

I wish to thank my adviser, Dr. Don Dell, for his support and guidance throughout this project and all my graduate work in my four years at The Ohio State University. I would also like to thank the members of my Dissertation Committee, Dr. Rich Russell and Dr. Karen Taylor for their time, helpful suggestions, guidance, and instruction.

The process of completing this project and my graduate education in general, has been influenced by some extraordinary friends and colleagues that I have had the privilege to know. I thank Jason Purnell, for first believing in my ideas and then helping me form them more clearly. I am thankful for his help with participant recruitment and for allowing me to use his Global Assessment of Spirituality Inventory in this study. I am also grateful to him for his encouragement, hours of discussions, honesty and thoughtfulness, and most of all, ever-present support.

I am grateful to Leslie Wade, who has been my roommate, my friend, my classmate, my colleague, my consultant, my statistics resource, my support system, and my family. Without her, these last four years would have been so much more difficult and so much less enjoyable. I don’t have the words to express properly all that she has given me and continues to give every day. 
I am thankful for Szu-Hui Lee who has brought so much caring, acceptance, support and understanding into my life. I am not sure how I would have gotten through the many hurdles of graduate school without her. She inspires me with her dedication to her work and her love for her friends and family.

I would like to thank Erica Claman for her help with this project. Her assistance with idea development, editing, and participant recruitment has been invaluable in completion of this study.

I would like to thank Sarah Reimer for her support during this process. Her encouragement and understanding came at just the right moments. Her caring, support, and humor made this process so much easier.

I would also like to thank Veronica Leal, Veronica Orozco, Amanda Scott, Michelle See, Melissa and Jim Wade, Dina Goldstein for their constant support, encouragement, and assistance during this process and throughout my graduate education.

Most of all, I would like to offer my gratitude to my family for offering me their love and unwavering support. Their love for me and their pride in my accomplishments has made it so much more meaningful for me to move through these milestones of education and life. They are my base, my rock, and my support system, and for that, I am eternally grateful. 
VITA

April 24, 1979..............................Born - Zhitomir, Ukraine

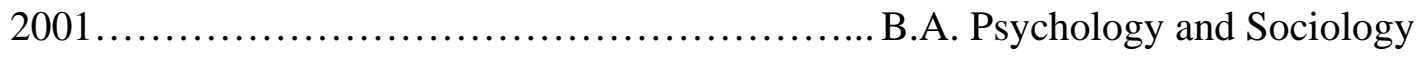
The University of Texas at Austin

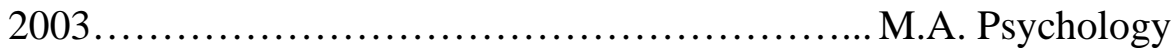

The Ohio State University

2001-2003..................................... Graduate Administrative Associate

Women student Services

The Ohio State University

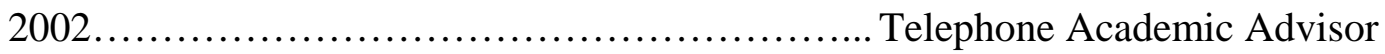
The College of Arts and Sciences The Ohio State University

2003-2004..................................... Graduate Administrative Associate Psychology Advising Office The Ohio State University

2004-present............................... Part-Time Faculty Sinclair Community College

2004-present. Graduate Teaching Associate The Ohio State University

\section{PUBLICATIONS}

1. Kakhnovets, R. (2003). “Counseling is just not for people like me:” Personality and expectations about counseling as predictors of help seeking attitudes. A Masters Thesis defended on April 16, 2003. The Ohio State University. 


\section{FIELDS OF STUDY}

Major Field: Psychology

Area of Concentration: Counseling Psychology 
TABLE OF CONTENTS

Page

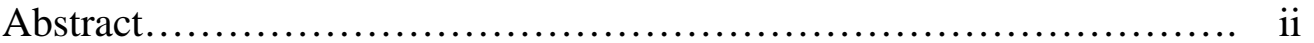

Dedication.............................................................. iv

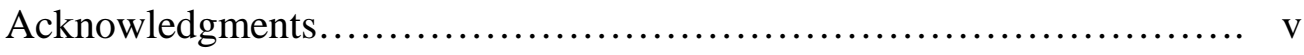

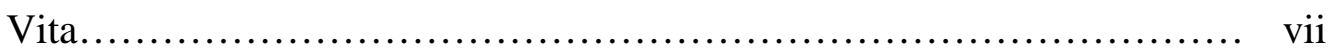

List of Tables....................................................... xii

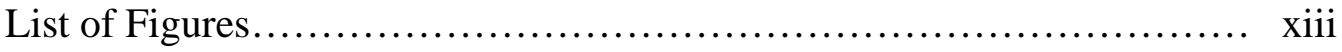

Chapters:

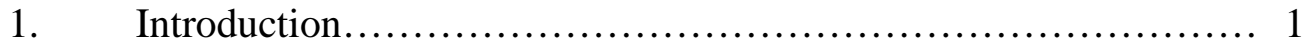

2. Literature Review.............................................. 10

Definitions.................................................... 10

Ethnic Identity.............................................. 14

Who is a Jew?............................................... 15

Jewish Identification....................................... 16

Jewish Identity............................................. 21

Social Identity Theory and Collective Self-Esteem................. 28

Self-Protective Functions of Collective Self-Esteem................. 31

Subjective Well-Being......................................... 36

Religiosity and Spirituality..................................... 38

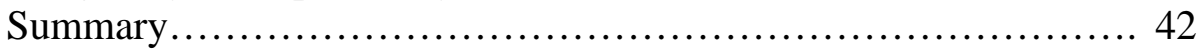

3. Method..................................................... 48

Participants................................................. 48

Participant Recruitment........................................ 49

Instruments.................................................. 51

Multigroup Ethnic Identity Measure..................... 52

National Jewish Population Survey Identification Scale...... 53 ix 
Collective Self-Esteem Scale, Race Specific Version......... 54

Global Spirituality Assessment Inventory................ 55

Religious Orientation Scale............................ 56

Rosenberg Self-Esteem Scale......................... 56

Center for Epidemiological Studies Depression Scale....... 57

Satisfaction with Live Scale.......................... 57

Demographic Questionnaire........................... 58

4. $\quad$ Results................................................... 59

Descriptive Statistics..................................... 59

Sample Comparison...................................... 60

Ethnic Identity, Well-Being, and Identification Scores............ 62

Religious Affiliation....................................... 63

Correlations.................................................. 69

Regression Analysis........................................... 70

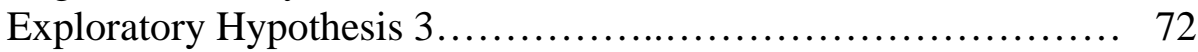

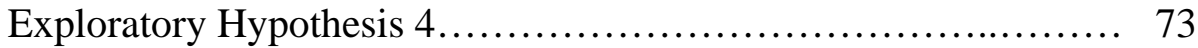

Being a Jew in America Means:.............................. 74

5. Discussion............................................... 76

Sample Differences......................................... 77

Jewish Ethnic Identity.................................... 79

Jewish Identification....................................... 80

Religiosity and Spirituality................................. 81

Moderation Effects........................................... 83

Exploratory Hypothesis.................................... 84

Implications and Directions for Future Research.................. 86

Limitations.................................................. 87

References...................................................... 88

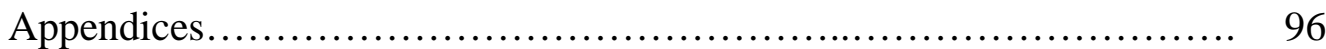

A. Tables................................................. 97

B. Recruitment Email for Research Experience Program..............105

C. Recruitment Email for Community Sample.......................107

D. Study Information and Consent ........................... 109

E. Debriefing Information................................ 113 
F. Instruments............................................115

Multigroup Ethnic Identity Measure.................... 116

National Jewish Population Survey Identification Scale..... 118

Collective Self-Esteem Scale, Race Specific Version......... 120

Global Spirituality Assessment Inventory, Revised Version. 121

Religious Orientation Scale........................... 125

Rosenberg Self-Esteem Scale.......................... 127

Center for Epidemiological Studies Depression Scale....... 128

Satisfaction with Live Scale.......................... 130

Demographic Questionnaire........................... 131

Prescreening Questionnaire............................ 132 


\section{LIST OF TABLES}

Table

1. Descriptive Statistics for All Variables............................. 97

2. Comparison of means for the Research Experience Program Sample and the Community Sample for All Variables....................... 98

3. Comparison of Means for Gender for the Research Experience Program Sample.

4. Comparison of Means for Gender for Community Sample....

5. Means for Variables That Significantly Differ by Religious Affiliation for the Community Sample...

6. Correlations Between Scores on MEIM Ethnic Identity, Collective Self-Esteem, Satisfaction with Life, Depression, Self-Esteem, Intrinsic Religiosity, Extrinsic Religiosity, Global Spirituality, Jewish Activities and Membership, Jewish Religious Activities, Jewish Ethnic Identity Factor, Well-Being Factor, and Identification Factor for the REP sample and the Community Sample...

7. Regression Analyses for Prediction of Global Spirituality, Intrinsic Religiosity, and Extrinsic Religiosity by Ethnic Identity Factor and Identification Factor for the Community Sample........

8. Regression Analyses for Prediction of Global Spirituality by Ethnic Identity Factor and Identification Factor for the REP Sample. 


\section{LIST OF FIGURES}

Figure $\quad$ Page

1. Nomological Network A: Relationship between Jewish ethnic

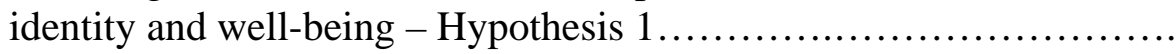

2. Nomological Network B: Relationship between Jewish ethnic identity and religiosity and spirituality moderated by Jewish

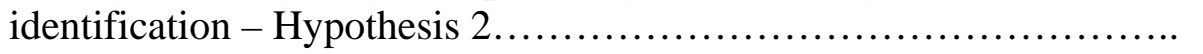




\section{CHAPTER 1}

\section{INTRODUCTION}

In discussions of issues of cross-cultural psychotherapy, a comparison is often made between White or Caucasian or European American therapists and clients and their African American, Asian American, American Indian, and Latino counterparts. The assumption in this kind of a comparison is that being part of the White, or dominant, group means that one is a member of that cultural group, is often perceived as an oppressor of others, and cannot understand the implications and intricacies of prejudice. Being lumped into this one group implies a shared set of values, a common history, and the same sense of privilege. This can be understood when looking at the history of Psychological research, most of which has been conducted using Caucasian participants. The fact that so much research about one race exists, makes it easy, almost natural, to compare other groups to it. Also, since most of the counselors today are White, it makes sense to look at the dyads involving a European American counselor and a client of color. The problem arises when this kind of thinking marginalizes entire groups of people and implies that their experiences are unimportant. The Jewish people are one group that has been consistently ignored in research and discussions of cross-cultural psychology. 
An argument can be made that the groups discussed in cross-cultural psychology are ethnic and cultural groups and not religious groups. Since the dynamics between counselors and clients of different ethnic and racial groups are complicated and not yet fully understood, it would make things even more complicated to also look at factors such as socioeconomic status, sexual preference, and religion. The issue with the Jews, however, is that they are not just a religious group. Langman (1995) stated:

Being Jewish, however, means more than belonging to a religion. Jews have been called a religious group, a people, in ethnicity, a culture, and a civilization. Some Jews are primarily religious and center their lives around Judaism. Others are primarily ethnic, maintaining the traditional foods, customs, songs, and so forth, that constitute a culture. There are 'political Jews' whose main sense of Jewishnes comes from the support of Israel or fighting anti-Semitism (p. 228).

Defining Jews as just members of a religious group means ignoring all the other aspects of Jewish life and what it means to be a Jew. A statement by one person speaks to this point, "I may be an atheist, but I'm a Jewish atheist” (quoted in Frommer \& Frommer, 1995, p. 190). This individual, like many other Jews, sees himself as a member of the group, even though he does not subscribe to the religious beliefs of Judaism. Peter Lamish stated that "All attempts to categorize or identify Jews as an ethnic, religious, or national group are simply inadequate and incomplete...Perhaps the closest any identification can come is to view the Jews holistically as a culture” (Lemish, 1981, p. 28). Another statement on this subject speaks to the difficulty of put Jewish people into one identifying category. Rabbi Hayim Donin stated:

This sense of kinship felt by the Jewish people may be more of a "mystical" experience than of a rationally definable one. Perhaps this is one of the reasons why Jews have never quite been able to fit into the convenient categories used by historians or sociologists to define nations, 
races, religions, and other social groupings. Except for the fact that the Jews obviously do not constitute a race (for race is a biological designation), the Jews are not just a religious faith, even though they are that; and they are not just a nation, even though they are that too, according to definitions of the term "nation." The problem is usually resolved by using the term "people” instead of either "faith" or "nation." (1991, p. 9; italics in original)

An important article in the field of psychology by Sue, Arredondo, and McDavis (1992) discussed ethical standards for the multicultural training of counselors. These authors defined competency as awareness of personal biases, knowledge of other cultures, and the use of culture-appropriate interventions in therapy. Sue et al. stated that “multiculturalism is inclusive of all persons and groups” (p. 81). However, it seems that at least one group has been left out. In order to investigate the contention that Jews are not included in multicultural and cross-cultural discussions, Weinrach (2002) examined textbooks on multicultural counseling used for counselor preparation. After identifying several books published between 1995 and 2000 whose primary focus was on multicultural/diversity-sensitive counseling and whose titles included any of the words culture/cultural/transcultural, diverse/diversity, ethnic/ethnicity, multicultural/multiculturalism, pluralism, prejudice, and race/racial/racism/interracial, Weinrach searched the index of these books for the following key words-anti-Semitism or Jew/Jews/Jewish/Judaism. The results of this search indicated of the 43 textbooks analyzed, 27 had neither an entry for anti-Semitism nor for Jew/Jews/Jewish/Judaism. One textbook had an entry for anti-Semitism, but none for Jew/Jews/Jewish/Judaism. Twelve had an entry for Jew/Jews/Jewish/Judaism but not for anti-Semitism. Only three of the analyzed books had entries for both anti-Semitism and Jew/Jews/Jewish/Judaism. 
It is important to note that only indices (or in the absence of an index, table of contents) were searched for the aforementioned terms. This is a limitation of the study, since if the references to anti-Semitism or variation of Jews was made in the text, but not mentioned in the index or table of contents, it was not counted in this study. Despite this limitation, Weinrach (2002) argues that the lack of inclusion of anti-Semitisms or Jew/Jews/Jewish/Judaism in texts written by well respected professionals in the field, used to educate future counselors, is an indication that Jews are systematically excluded from the multicultural conversation and are thus discriminated against.

Weinrach (2002) also examined the articles published by the Journal of Counseling and Development (and its predecessor The Personnel and Guidance Journal) for the years of 1979-1999. The findings indicated that across the 20-year span of approximately 2,400 articles, only 72 of them had the words anti-Semitism or Jew/Jews/Jewish/Judaism appear at least once. In other words, one or more of these keywords appeared in about 3\% of all the published articles. Weinrach states that for most of the 72 articles, the aforementioned terms appeared as a reference in a list of other names or as a single term used to describe someone as opposed to a more involved discussion of the topic (2002). This too, is an example of exclusion, whether intentioned or not, of Jews from Counseling Psychology.

In his examination of the exclusion of Jewish issues from counseling psychology, Weinrach (2002) concluded that "In the aggregate, the compendium of incidents previously described would suggest a pattern of widespread denial of the existence of anti-Semitism and a repudiation of the importance of Jewish issues in the counseling 
profession” (p. 310). Robbins (2000) stated that "unfortunately, there has been less research specifically on the Jewish population than on many other ethnic minorities” (p. 4).

It is apparent that there is some evidence of exclusion of Jews from the discussion of multicultural and cross-cultural issues. The obvious question in light of this is "Why?" What factors have lead to this omission? And once this is figured out, what can be done? Some reasons, proposed by Langman $(1995,1999)$, for the fact that Jews may have been excluded from multiculturalism may be the level of assimilation of American Jews, the classification of Jews as White, the idea that the Jewish people are a members of a religious group, not culture, the perceived economic status of Jews, and the exclusion of anti-Semitism from the discussion of the other isms (i.e. racism, sexism). Also, Jews themselves have not focused on Jewish issues. This may be because they have felt the need to separate their public and private identities, felt the lack of validation for their experiences as members of a minority group, their fear of being publicly Jewish, and in some instances, self-hatred or internalized anti-Semitism (Langman, 1995).

One reason that the Jewish people may not be included in the cross-cultural discussion is that they are viewed as simple mainstream Americans, and thus there is no need to include them in such a discussion (Langman, 1995). However, as mentioned earlier, even the non-observant Jews identify themselves as members of the group. Being Jewish does not necessarily mean practicing Judaism. It means feeling a part of a group with a common history, set of traditions and customs, and ties to Israel. Isaiah Berlin (as sited in Whitfield, 1999) best captured the essence of being part of the Jewish group 
through a rhetorical question and then an answer. He asked “' What does every Jew have in common, whether he hails from Riga or from Aden, from Berlin or from Marrakesh or Glasgow?” (p. 14). To which he replied: “’A sense of unease in society. Nowhere do almost all Jews feel entirely at home”' (p. 14).

The fact that the Jewish people are a minority is not widely acknowledged. Taking a closer look at the population of the world and of the United States, the minority status of the Jewish people can be clearly seen. According to the World Almanac (1994), Jews are approximately $1 \%$ of the world's population. Even in the United States, Jews comprise only $2.5 \%$ of the population. The word minority, however, typically refers to race. The World Almanac (1994) indicates that although the U.S. is 83\% White, it is 95\% Christian. So while being non-White constitutes being a part of a minority group, being non-Christian is even more rare (Langman, 1999).

When discussing race, Jews are most often put into the White category. However, even this has its own problems and history. Jews are not a race. A race is biological, and cannot be chosen, while one can choose to become Jewish. There are Jews of many races: Black, White, Asian, Hispanic, and Native American (Langman, 1999). The fact that to be Jewish does not mean that you are part of a different race does not mean that Jews have not been considered as such in the past. In Europe, Jews were considered as non-White for centuries. The theory of the time was that they had intermarried with Africans, and thus were black (Gilman, 1991). The Nazis also did not consider Jews as white. They classified Jews as the darker race, and non-Aryan. Even in America, as recently as late nineteenth and early twentieth century, Jews were considered members of 
an "alien race” (Langman, 1999). Thus, considering Jews as White, is a fairly new phenomenon. "The linguistic move of substituting 'people of color' for 'oppressed minorities,' coupled with the decision to refer to Jews as 'Whites,' becomes an antiSemitic denial of Jewish history” (Lerner, 1992, p. 123).

A common stereotype of Jews is that they are rich and greedy. This view may lead to a conclusion that they do not need help or the attention that other groups do. While as a group, Jews are better off than some other minorities, not all Jews are well off. A study conducted by the Metropolitan New York Coordinating Council on Jewish Poverty found that 22 percent of Jewish households in Brooklyn are below the poverty level (1993). While this is an example from only one community, it still speaks to the point that not all Jews are wealthy. Also, it is important to remember that financial affluence does not prevent oppression (Langman, 1999). Even those Jews who are wealthy, face some of the same issues as do poor Jews.

Most students and professionals in the field of psychology are familiar with discussions of racism, sexism, and homophobia. However, anti-Semitism is a form of discrimination that has been left out of the conversation. One reason for this could be because people just do not know about the oppression that Jews face. As recently as 1950's and 1960’s, signs like “No Jews or dogs allowed,” or “Adverse to association with Hebrews" appeared in hotels. Job advertisers frequently specified "Christians only" in their postings (Langman, 1999). Even today, such extreme discrimination exists. One form of this anti-Semitism is Holocaust denial. There are those who claim that the 
Holocaust never happened, or was not as bad as Jews claim it was. Even a suggestion of this is a slap in the face to members of a group who lost over six million members in this atrocity.

Through history of anti-Semitism, Jews have learned to separate their private selves from the public selves that they present. This has been a survival technique. Seeming "too Jewish" is something to avoid. Because that Jewish Americans are mostly unrecognizable on site (unlike some other minorities) they may not be constantly aware of their ethnicity (Langman, 1999). This has also allowed them to separate their Jewish identity from their public face and to be able to hide behind their American identity. While this has allowed them to escape some anti-Semitism, it also implies that there is something wrong about being Jewish, and this it must be kept private. This separation of identities may be a reason why Jews in psychology have not done much to promote the needs of Jews. In fact, some report that it has never occurred to them to include their Jewishness in their professional lives (Langman, 1999).

Another reason that Jewish psychologists have not fought for inclusion of Jews in multiculturalism is internalized anti-Semitism. This refers to the concept of disengaging oneself from the Jewish culture and denying the existence of anti-Semitism. This concept is comparable to African Americans rejecting their culture, identifying with the white culture and denial of racism (Cross, 1995). This internalized anti-Semitism obscures the reasons that Jews should be included in the discussion of minority groups and thus Jewish professionals are not speaking out on behalf of their group (Langman, 1999). 
It is conceivable that the separation of the American and Jewish identities, or trying not to be "too Jewish" in public and at worst, internalized anti-Semitism may lead to some serious psychological problems. "Being Jewish in an non Jewish society potentially creates a conflict of identification. Jews frequently fell lesser in comparison to non Jews and are also ashamed of being different” (Kaufman \& Raphael, 1987, p. 30). Some psychological issues like low self-esteem, depression, or a diminished sense of overall well-being may be the consequences of this conflict, especially for those Jews who hold a negative self-image or self-identity or feel disconnected from members of their group and the dominant culture.

It seems that some evidence exists that Jews have been left out of the crosscultural discussion. Also, there are a lot of reasons for why this may be happening. This brief overview of some issues faced by American Jews points to some very important concerns. Some questions that arise are: What kinds of psychological issues do Jews in America face? How do American Jews think of their identity? What kinds of concepts are associated with strong and weak Jewish identities? This study attempts to answer some of these questions. In particular, this study investigates the relationship between Jewish ethnic identity well-being, religiosity, and spirituality for American Jews. The relationship between Jewish identity and identification is also investigated. Psychologists long enough have overlooked American Jews. It is time to study their identity development and offer psychological services that may help this community function better psychologically as a minority group in the United States. 


\section{CHAPTER 2}

\section{LITERATURE REVEIW}

During the last few decades, the field of psychology has seen the rise of research dealing with racial and ethnic minorities. Much discussion has been occurring on the issues faced by the different groups and on their racial and ethnic identities. As the previous section of this paper indicates, one such group has been left out of the conversation. This study will explore the concept of Jewish Ethnic Identity and its correlates. This section of the paper will review the relevant concepts and provide some hypotheses. In particular, this section reviews the concepts of race, ethnicity, culture and identity and relate these to the Jewish people. Also, a study of Jewish identity and the related psychological issues will also be presented.

\section{$\underline{\text { Definitions }}$}

Helms (1993) states that many people erroneously use the person’s racial categorization (e.g. Black, Asian) for his or her racial identity. She states that the term “racial identity” refers to a “sense of group or collective identity based on one’s perception that he or she shares a common racial heritage with a particular racial group” (p. 3). Ethnicity has also been an illusive term, without clear definition and used often 
interchangeably with terms such as race and culture. "Despite the greatly increased interest in recent years in the problems of ethnicity, little has been done by way of systematic analysis of the structure and dynamics of any ethnic identity (Herman, 1989, p.27). Identity is yet another term that has been used inconsistently, often to refer to different concepts. Since there is so much confusion in the United States over the terms of race, ethnicity, and culture, and identity, it is important to define these before a definition of an ethnic or cultural identity can be presented. This section will present definitions of these terms as conceived by various authors and researchers in the field of multicultural and cross-cultural psychology.

Krogrman (1945) defined race as "a sub-group of peoples possessing a definite combination of physical characters, of genetic origin, the combination of which to varying degrees distinguishes the sub-group from other sub-group of mankind” p. 49. Thus, race is seen as biological and the definition presented has no behavioral, psychological, or social implications on its own (Casas, 1984). It is what people believe, think or feel about their race that can have implications for individuals' functioning (Helms, 1993).

Casas (1984) defined ethnicity as “a group classification of individuals who share a unique social and cultural heritage (customs, language, religion, and so on) passed on from generation to generation” (p. 787). Casas also points out that ethnicity is not a biological phenomenon, and thus the terms race and ethnicity cannot be used 
interchangeably. Thus, members of different racial groups could belong to the same ethnic group and members of different ethnic groups could belong to the same racial group (Helms, 1993).

A definition of culture provided by Marsella and Kameoka (1989) is as follows:

Culture is shared learned behavior that is transmitted from one generation to another for purposes of human adjustment, adaptation, and growth. Culture has both external and internal referents. External referents include artifacts, roles, and institutions. Internal referents include attitudes, values, beliefs, expectations, epistemologies, and consciousness. (p. 233)

Ridley, Li, and Hill (1998) support this definition of culture because it includes internal and external dimensions and acknowledges that culture touches on many aspects of people's lives. Barth points out that culture is the result of, rather than the primary characteristic of ethnicity (Barth, 1969).

Miller (1963) defines identity as “the patterns of observable or inferable attributes ‘identifying’ a person to himself and others” (p.673). Identity refers both to a person’s likeness and difference with other members of his or her group of reference (Herman, 1989). According to Erickson (1968), "identity achievement is the secure sense of self and it the optimal outcome of the identity formation process; an unsuccessful resolution of identity issues results in identity diffusion, indicated by lack of clarity about oneself and one's place in society” (Phinney, 1992; p. 160). Thus, the process of ethnic identity formation involves the exploration of the meaning of one's ethnicity that ultimately leads to a feeling of a sense of oneself as a member of the group (Phinney, 1989).

Ethnic identity, defined by Tajfel (1981) and Phinney (1992) is "that part of an individual's self-concept that derives from his or her knowledge of membership in a 
social group (or groups) together with the value and emotional significance attached to that membership (Phinney, 1992; p. 156). Previous studies that have focused on exploration of ethnic identity of different groups (Parham \& Helms, 1981; Garcia, 1982; Zak, 1973; Constantinou \& Harvey, 1985, and Ting-Toomey, 1981), have identified some important aspects of ethnic identity. These included self-identification, language, social networks, religious affiliation, endogamy, positive attitudes, and cultural practices and traditions (Phinney, 1992). "It is clear that each group has its unique history, traditions, and values; yet the concept of a group identity, that is, a sense of identification with, or belonging to, one’s own group, is common to all human beings” (Phinney, 1992, p. 158). Phinney (1992) warns that it is important to note that while different individuals may self-identify as being members of the same group, their sense of belonging to that group, attitudes about the group, ethnic behaviors, and their understanding of the meaning of their ethnicity may vary greatly.

Phinney (1992) also differentiates between self-identification and ethnic identity. Self-identification is a label that an individual uses for oneself. Ethnicity is the objective group membership as determined by parent's ethnic heritage. Self-identification may differ from ethnicity for some individuals (Singh, 1977). Thus to study an individual's ethnic identity, it is important that he or she self-identify with that ethnic group.

From the previous discussions of race, ethnicity, culture and identity, some conclusions can be drawn. Jews do not constitute a race because it is a biological distinction. There are Jews of different races in the world, so being Jewish cannot mean that you are a member of a specific race. For the purposes of this study, Jews will be 
considered members of an ethnic group. Jews as a group have a common history, a language, a religion, a nation, and a culture. According to Barth (1969) culture is a result of an ethnic group, not a determinant of it, and thus Jewish culture is the outcome of Jewish ethnicity. “'Being Jewish' is not simply a matter of individual faith, but also of folk, or ethnic heritage and group life. Thus the religious paradigm does not account for the unique role of historical experiences in Jewish life” (Bock, 1976, p. 44).

\section{Ethnic Identity}

Tajfel (1978) states that membership in a minority group can create a psychological conflict for individuals. The members of such groups face a choice between accepting the majority views of them (which are usually negative) or rejecting these views in search of their own identity. This choice can create a psychological conflict, and thus some members of minority groups develop a negative self-identity and self-hatred (Phinney, 1989). Cross, Smith, and Payne (2002) discuss the concept of "buffering” which refers to the practice of using one's own ethnic identity as a shield against racism or other methods of discrimination from the majority society. Although Cross et al. (2002) discuss "buffering" in relation to African American, this concept can be useful when discussing other minority groups. Since one's racial or ethnic identity can serve as a protective shield from the negative views of the majority culture, those individuals who have stronger ethnic identities may be more successful in protecting themselves from internalizing negative messages coming from the oppressing group.

Previous studies indicate that ethnic identity is correlated with self-esteem measures for high-school students. At the college level, this relationship was still present 
for minority students, but not for the White students (Phinney, 1992). Another study that focused solely on college-aged students indicated that correlations between self-esteem and ethnic identity were higher for ethnic minorities than for White students (Phinney \& Alipuria, 1990). However, Phinney (1992) reported that the White students who attended schools where Whites were in the minority, showed the same patterns of relationship between ethnic identity and self-esteem as did the minority students. This may indicate that when ethnic identity is made salient by minority status, its relationship to self-esteem of the individual is more evident. It is important to notice that in this study, participants completed the Multigroup Ethnic Identity Measure (Phinney, 1992), where they were instructed to self-identify in an open-ended question. Some of the White students identified as Polish or Irish-American ethnic groups, but because their numbers were small, their responses were examined in the same group as the rest of the White students (Phinney, 1992). Thus, for some individuals, being White seems to be too broad of a category and further investigation into their ethnic identity may be necessary to see how they may compare to those individuals who only indicated that they are White.

\section{Who is a Jew?}

Before a discussion of Jewish identity and identification can take place, it is important to first answer the question of "who is a Jew?" According to Jewish religious law (the "halacha”) a person is a Jew if he was born to a Jewish mother or converted to Judaism according to prescribed procedures. "A mere declaration of faith or of the feeling of belonging does not make a person a Jew. Nor does a person cease to be a Jew because of either lack of faith or of sense of belonging” (Herman, 1989, p.76). 
This definition of a Jew has been accepted for many years. However, with the increasing rate of intermarriage, more and more children are born to Jewish fathers and non-Jewish mothers. The National Jewish Population Survey 2001-2002 (NJPS; United Jewish Communities, 2003) surveyed over 5,000 Jews in the United States. These surveys were conducted over the phone for a period of a year. For the purposes of this study, Jew was defined as a person:

- whose religion is Jewish, or

- whose religion is Jewish and something else, or

- who has no religion and has at least one Jewish parent or a Jewish upbringing, or

- who has non-monotheistic religion and has at least one Jewish parent or a Jewish upbringing (United Jewish Communities PowerPoint Presentation of Findings, 2003)

While the current Jewish stance on this issue is unclear and controversy in the Jewish community over this topic exists, for the purposes of this study, a Jew is considered to be anyone born to a Jewish parent or anyone who has converted to Judaism according to either Orthodox, Conservative, or Reform traditions, or anyone who has had a Jewish upbringing.

$\underline{\text { Jewish Identification }}$

In his writings on Jewish identification and identity, Himmelfarb $(1980,1982)$ reviews the relevant work that has been done in the field relating to this topic and states that most studies to date have focused on Jewish identification and not on Jewish identity. Himmelfarb (1982) defines Jewish identity as one's sense of self with regard to being Jewish. It is an important part of one’s self-concept or self-definition. "Jewish identity, of what being Jewish means, of what kind of Jew and what kind of Jewishness develop in 
the majority culture” (Herman, 1989, p. 28.). Identification is defined as the extent to which the behavior and attitudes of Jews are Jewishly oriented (Himmelfarb, 1980). Thus, in his review of works on the subject, Himmelfarb focuses on Jewish identification. While identification in the sense described here does not encompass all the concepts that this paper proposes to study, it is nevertheless important.

Upon examining some previous works (Verbit, 1970; Lazerwitz, 1973, 1978; and Bock, 1976), Himmelfarb (1980) concludes that Jewish identification is a multidimensional phenomenon and there are seven dimensions that are common in the reviewed studies. These dimensions include:

1. ritual behavior

2. formal organizational participation

3. informal social ties with other Jews (friends, neighbors, mates).

4. attitudes toward Israel

5. doctrinal belief

6. some intellectual dimension (having, or seeking knowledge)

7. some measure of charity giving

There are of course differing opinions on how many dimensions of identification there are and how these dimensions load onto larger concepts. Bock (1976) stats that there are ten dimensions and that these can be divided into two larger categories of public and private Jewishness. Further research in this area is still needed to determine the various dimensions of Jewish identification and to see how these relate to Jewish identity.

Previous studies show that there are several factors that influence how individuals identify themselves as Jews. Denominational (Orthodox, Conservative, Reform) selfidentification has been shown to be related to how individuals score on Jewish 
identification measures with Orthodox Jews scoring the highest and Reform Jews scoring the lowest (Himmelfarb, 1979; Himmelfarb \& Loar, 1979).

Since the social context in which some Jews live influences the opportunities and challenges that they can face, several factors of the social environment have been found to be related to Jewish identification. Studies show that the greater the distance from the immigrant generation, the more Jewish identification declines (Goldstein \& Goldscheider, 1968; Axelrod et al., 1967). The only exception to this finding is the adherence to certain rituals (i.e. attending Passover Seder or lighting Hanukkah candles). Sklare and Greenblum (1967) explain this exception:

Five criteria emerge as important in explaining retention of specific home rituals. Thus the highest retention will occur when a ritual: 1 ) is capable of effective redefinition in modern terms, 2) does not demand social isolation or the adoption of a unique life style, 3) accords with the religious culture of the larger community and provides a "Jewish" alternative when such is felt to be needed, 4) is centered on the child, and 5) is performed annually or infrequently (p. 57, as quoted in Himmelfarb, 1980).

Suburban Jews tend to be less identifying than urban Jews (Goldstein \& Goldscheider, 1968). This is an interesting finding to consider. Do suburban Jews identify less because that is the nature of the people who tend to live away from the bustle of the city, or do the social conformity pressures of suburbia force the Jews living there assimilate more into the dominant culture? Further research is required to answer these questions.

Family influences appear to be strongly related to individual's level of Jewish identification. Previous studies have found that there is a positive relationship between an individual's Jewish identification and that of his or her parents (Sklare \& Greenblum, 
1967; Lazerwitz, 1973; Bock, 1976). This relationship seems to extend from childhood though adulthood. The mechanisms by which parents influence their children's identification have not been explored through research. Some possibilities could be raising children in a Jewish home, following the Commandments; enrolling children in Jewish schools; socializing with other Jewish families; and encouraging Jewish marriage.

The peer group that an individual is around, also seems to be an important influence on his or her Jewish identification (Dashefsky \& Shapiro, 1974). In fact, Rosen (1965) found that in cases when the peer group and parental influences are in conflict, the peer group is often more influential. Thus exploring the peer groups that individuals may be around may be important in investigations dealing with Jewish identification.

Several studies have examined the impact of various forms of Jewish education on Jewish identification. The Jewish community spends great amounts of money and effort on Jewish education in order to preserve the community. Studies like Cohen (1995) examine the effectiveness of these efforts to produce Jews who will engage in more Jewish activities, marry within the Jewish community, and encourage their children to be active, educated Jews. The Jewish education systems examined by Cohen (1995) were the formal schooling and informal education. Formal schooling includes Orthodox day schools, non-Orthodox day schools, part-time schools, and Sunday schools. The methods of informal education examined in this study were youth group, travel to Israel, and educationally intensive summer camps. Cohen (1995) found that most types of Jewish education raise levels of Jewish involvement. Sunday schools were the single 
exceptions to this finding. The author hypothesizes that the minimal amount of time and commitment involved in the Sunday school education may be related to the lack of influence this type of education has on Jewish identification.

The effects of Jewish education seem to persist into adulthood and beyond marriage. Jewish education increases the chances that Jews will marry Jews. For those Jews who marry Jews, if they had Jewish education, the likelihood that as adults they will have more involvement in Jewish life is higher than for those Jews who did not have such education (even if these Jews are married to Jews) (Cohen, 1995).

Jewish identification is hypothesized to be related to an individual's Jewish identity. It seems to be intuitive, that those who find Jewishness important to their selfconcept will participate in Jewish activities. Kivisto and Nefziger (1993) found that identification seemed to be positively associated with felt importance of being a Jew.

All individuals interact with their families, peer group, ethnic community and wider culture. Within each of these milieu, the need to identify presses for expression. It is through feeling identified with parents, with peers, and with one's particular ethnic-religious group, as well as the wider culture, that one ultimately experiences inner security. Through positive identification with others, a sense of belonging grows. (Kaufman \& Raphael, 1987, p.31)

The question that arises is whether not identifying by not participating in traditionally Jewish activities (i.e. synagogue attendance, affiliation with Jewish organizations, etc.) means that the individuals consider their Jewishness unimportant to their self-definition. In other words, does the lack of identification mean that the individuals' Jewish identity is not important? 


\section{Jewish Identity}

The study of Jewish identity has to take cognizance of the peculiar interweaving in such identity of national and religious elements. Judaism is not just a religious creed analogous to Christianity. It is the religious civilization of one particular nation, it resides in the Jewish people and reflects its history. And the Jewish people is what it is because of this religious civilization (Herman, 1989, p. 36).

This statement by Herman (1989) points to only some of the complexities that underlie Jewish identity. Jews all over the world have for centuries lived as members of a minority community among the dominant culture. Assimilation, national pride, national identity, anti-Semitism, fear of rejection by the dominant culture and the history of being exiled from many different countries have all influenced the Jewish identity. An independent state of Israel, although a much desired thing of many generations of Jews is only a recent development. The way that Jews live, interact with their surroundings, and think of themselves as Jews is likely to be different in Israel, the United States, and other countries of the world. For example, the sheer fact of not being in the minority may make the experience of being a Jew different for Israeli Jews from that of American Jews who exists as members of a very small minority. “A Jewish identity exists nowhere in isolation as the sole ethnic identity of an individual. The Jewish Identity of an American Jew can only be understood in the context of his Americanism” (Herman, 1989, p. 56). For these reasons, this investigation will focus on the issues of Jews residing in the United States of America.

"Scattered as they are across the globe, the Jews adopt everywhere the language and customs of the majority cultures, but at the same time, despite the diversity, maintain a kernel of sameness which may be termed 'Jewish'” (Herman, 1989, p. 24). 
Zak (1973) investigated the relationship between an individual’s Jewish identity and American Identity. Previous researchers hypothesized that there is a bipolar relationship between the two identities. That at some point, an individual adheres to the Jewish identity, while at other points, the American Identity is more salient (Herman, 1962). Zak, however, in his research took a view that these two identities can coexist in the same individual in an orthogonal way, not interdependent of each other. "Is being a Jew and being an American a conflicting or supplementary phenomenon? What is the content and what are the relations of such dimensions? Specifically, it was hypothesized that American-Jewish identity is composed of two relatively orthogonal dimensions, one dimension reflects the Jewish identity components, while the other comprises the American identity ones” (Zak, 1973, p. 892).

The participants of this study (Jewish college students, ages 17-25) completed the Jewish-American Identity Scale, a 20-item, seven-point, summated rating scale, which was derived from previous studies (Herman, 1962, 1970; Hofman \& Zak, 1969) and adopted for this investigation (Zak, 1973). The Jewish dimension of identity is defined as "the degree of the centrality of the Jewish group for the individual, the importance that one attaches to his Jewish belongingness, one's sensitivity to Jewish issues, and the feeling of interdependence of Jews in the world” (Zak, 1973, p. 893). The American dimension is "the individual's sense of belonging to American people. It is defined as the degree of importance of being an American, sensitivity to American issues, and the feeling of interdependence of the American people” (Zak, 1973, p. 893). 
The results of the study indicated that there exist two orthogonal dimensions of Jewish Identity and American Identity. Thus, a person may identify positively on both dimensions, or positively on one and negatively on another or negatively on both (Zak, 1973). These two dimensions of identity do not appear to be on the same continuum. Some limitations of this study may be that participants may have answered the questions in a socially desirable way, indicating that they care about America as well as Jews.

After phenomenological investigation of Jewish identity, Friedman, Friedlander, and Blustein (2005) conclude that most of the participants of their study see themselves as bicultural. The majority of the participants in this study described themselves as having two cultural identities, Jewish and America. For these individuals, there appeared to be one identity, however, that was more salient. The researchers found that there was a relationship between Jewish cultural identification and identity salience. For Orthodox Jews, their Jewish identity appeared to be more salient than their American Identity. The opposite was true for the participants who identified themselves as unaffiliated or less affiliated (Friedman, et al., 2005).

Friedman and collegues (2005) also describe various important themes of Jewish identity derived from their investigation. After interviews of 10 Jewish adults, the following themes appeared salient for the participants: experience of discrimination; feeling marginalized; desire to increase religious practices; sense of pride about being Jewish; congruency between cultural identity and religious practice; need for a better understanding of Jewish heritage; connection to Israel; valuing connections with other Jewish people and with non-Jews; importance of marrying someone who is Jewish; and 
the importance of family influence while growing up. All of the participants in this study also indicated that their Jewish identity is fluid and fluctuating. They stated that at some points in their lives their Jewish identity was particularly strong or salient and at other times, it was weaker. Mort of the increases in salience seemed to occur around important developmental milestones, like getting married, having children, etc. (Friedman, et al., 2005). All of the participants also indicated that it was important to them to pass down their Jewish culture to their children. In conclusion, the authors of this study state that “an American Jew’s ethnic identity is complex, multidimensional, and highly personal, its strength depending on the individual's identification with both the cultural heritage and the faith (Friedman, et al, 2005, p. 82).

In their research on Jewish ethnic identity Kivisto and Nefzger (1993) found that the Jewish participants indicated five different characteristics as being important in determining what it means to be a Jew. These included: sense of shared history; commitment to justice; belief in God; commitment to the Torah; and membership in a Temple or synagogue. It seems that these thing would be incorporated in an individual's Jewish identity. However, on closer look, at least one of these is a dimension of Jewish identification. The membership in a synagogue characteristic is an aspect that would speak to a person's identification. Thus, these results may suggest that identity and identification are related.

Experiences of identification provide needed support, strength and healing for an evolving self. Individuals identify in order to emulate those they admire, to feel at-oneness or belonging, and to enhance their own sense of inner power. From identification springs loyalties to family, to a religion, to a particular ethnic group. Loyalties create allegiances, whether to a 
political party or a nation. The need to belong to something larger than ourselves, to a group, cause or idea, is one principal source of identity (Kaufman \& Raphael, 1987, p. 31).

When studying Jewish Identity, several factors have to be taken into consideration. Herman (1989) lists these in his chapter on criteria for Jewish identity. These include:

a) the nature of the individual's relationship to the Jewish group as a membership group; and

b) the individual's perception of the attributes of the Jewish group, his feelings about them, and the extent to which its norms are adopted by him as a source of reference. (p.39)

Herman (1989) suggests that a big part of ethnic identity is the shared sense of belonging by the members of the group and at the same time, a feeling of differentiation from the rest of the society. Differentiation for the Jewish people means not only being different from the majority society, but also from all the non-Jews. Members of the group may feel differently about this demarcation. Those wanting to leave the group, and blend into the majority society, would want to be less distinct, and thus may leave some of the staples of their group behind, or seek to identify with their group only in private. The strongly identifying Jews may wish to separate themselves from the majority society and thus will draw boundaries between these groups and maintain their distinctiveness.

For the Jewish people, a sense of interdependence or of a common fate is also important in their ethnic identity. "When we speak here of interdependence we are using the term in the sense of a change in the state of any part affecting al the other parts. In the context of the Jewish life this means that whatever happens to Jews qua Jews anywhere has implications for Jews everywhere” (Herman, 1989, p. 43). This concept 
can be seen exemplified every time an act of terrorism happens in Israel. Jews all over the world feel the impact. "When interdependence is recognized as the basis of belonging, even Jews who see themselves as dissimilar from other Jews regard themselves as belonging to the Jewish group. The feeling of interdependence, of a common fate, represents the widest minimal basis, the common denominator, of Jewish belonging in our time” (Herman, 1989, p.43).

There are some studies that have focused on creating a measure of Jewish Identity (Segalman, 1966; Sarnoff, 1951; Zak, 1973; etc.). Most of these are outdated and have not been tested after the initial proposal (for a detailed critique see Cohen, 1977). However, it is important to discuss at least one of these measures. Cohen (1977) after a detailed critique of the work on Jewish identity to date, created a Jewish Identity Scale. This measure consists of six different dimensions, including: National Scale ("I think it is important that Israel remain a 'Jewish State’”); Reaction to Anti-Semitism Scale (“AntiSemitism is all around"); Racial Scale ("Jews can trace their blood lines back to the time of Moses"); Religious Scale ("I feel that the Torah is the revealed word of God"); Cultural Scale ("The Jewish sense of values is important in my life"); and the Interdependence of Fate Scale (“An unbreakable bond unties the Jews of all countries of the world"). The results of the study attempting to validate this scale supported the validity of the JIS (Cohen, 1977). The findings also indicate that while Jewish identity is composed of multiple dimensions, the scale was not a good measure of these separate dimensions. The scale also consists of items that seem to measure identity (meaning of being Jewish to the participant) and some that measure identification (participation in 
Jewish activities). This may account for some inconclusive results of this study. The author concludes that more research needs to be done to investigate the structure of Jewish identity.

A study examining the relationship between Jewish identity and self-esteem (Klein, 1977) found that those with positive Jewish identity had Jewish friends; actively participated in family observances of Jewish holidays and had positive memories of these celebrations; accepted their body image and did not wish to change their physical features to look more like their White, Anglo-Saxon, Protestant counterparts; associated valued personal traits with Jewishness; were willing to defend Israel; and connected to the Jewish past through some historical figure. Those had responses indicative of positive Jewish identity (on the open-ended questions) also had higher self-esteem and lower alienation scores than individuals with negative Jewish Identity (Klein, 1977, 1980). Klein (1980) states that those individuals who attribute their most positive and most negative traits to Jewishness tend to have the lowest self-esteem. Thus it seems like a conflict in one's identity, or Jewish identity in this case, may be related to such psychological concepts as self-esteem and alienation.

Another study examined the relationship between the ethnic identity of Jewish and African American residents in a long-term care facility (Sasson, 2001). The participants of this study were 71 Jewish and 21 African American residents age 65 and older. Interviews with participants were conducted to investigate participants' ethnic identity, adjustment, and satisfaction with residency. Ethnic identity was measured by the Multigroup Ethnic Identity Measure (MEIM; Phinney, 1992). Resident satisfaction 
was measured by the Nursing Home Resident Questionnaire (NHRQ; Kane, Riegler, Bell, Potter, \& Koshland, 1982). The measure of adjustment of each resident was based on the social worker's evaluation of the resident's performance in the following areas: overall adjustment, grievances issued to staff, and participation in activities. The results of this study indicated that ethnic behavior scale of the MEIM was the only ethnic identity measure that was significantly associated with resident adjustment and satisfaction. The two ethnic groups did not differ in their relationship of ethnic identity and adjustment and satisfaction (Sasson, 2001). This study indicates that while the results were not as strong for the whole ethnic identity measure, some parts of one's ethnic identity are related to satisfaction with and adjustment to life. Sasson (2001) indicates that further research is necessary on this topic.

\section{$\underline{\text { Social Identity Theory and Collective Self-Esteem }}$}

In their attempt to explain intergroup behavior and conflict, Tajfel and Turner (1986) describe the social identity theory. A group is defined "as a collection of individuals who perceive themselves to be members of the same social category, share some emotional involvement in this common definition of themselves, and achieve some degree of social consensus about the evaluation of their group and of their membership in it” (Tajfel \& Turner, 1986, p. 15). Social identity is defined as the way one sees oneself as a member of a group, including the feeling of affiliation to that group and the value one places on membership in that group (Tajfel, 1978). It is the aspects of one's self-concept that come from the group that this individual feels some sense of belonging 
(Tajfel \& Turner, 1986). The theory is based on the following assumptions:

1. Individuals strive to maintain or enhance their self-esteem: they strive for a positive self-concept.

2. Social groups or categories and the membership of them are associated with positive or negative value connotations. Hence social identity may be positive or negative according to the evaluations of those groups that contribute to an individual's social identity.

3. The evaluation of one's own group is determined with reference to specific other groups through social comparison in terms of valueladen characteristics (Tajfel \& Turner, 1986, p. 16).

Using these assumptions about individual's and the way they tend to behave in social situations, Tajfel and Turner (1986) derive the social identity theory which states that:

1. Individuals strive to achieve or to maintain positive social identity.

2. Positive social identity is based to a large extent on favorable comparisons that can be made between the in-group and some relevant out-groups: the in-group must be perceived as positively differentiated or distinct from the relevant out-groups.

3. When social identity is unsatisfactory, individuals will strive either to leave their existing group and join some more positively distinct group and/or to make their existing group more positively distinct (p. 16).

Thus it seems that the pressures to achieve a positive social identity may lead individuals to try and differentiate their own group through positive social comparison. In order to accomplish this, individuals must have an internalized sense of group membership, there must be an opportunity to make a comparison, and the target of comparison must be a relevant group (in-groups cannot compare themselves to all groups that exist) (Tajfel \& Turner, 1986).

In their discussions of social identity theory, Tajfel and Turner state that there are two different aspects of self-concept. These include individual identity and group 
identity (1986). "Whereas personal identity refers to how people view themselves as individuals, social identity refers to how they view the social groups to which they belong” (Luhtanen \& Crocker, 1992, p. 302). The value that people place on their group or social identity refers to their collective self-esteem (Luhtanen \& Crocker, 1992). "Racial or collective self-esteem refers to evaluations of the worthiness or value of the social groups - such as racial, ethnic or religious groups-of which one is a member" (Crocker \& Major, 1989, p. 609). In their discussions of collective self-esteem, Luhtanen and Crocker (1992) state that people try to maintain and enhance not only their personal identity, but also attempt to maintain a positive group identity.

Previous studies and theories of self-esteem have only focused on the individual dimension of this concept. However this seems to leave out an important factor in people's lives—-their views and feelings about the groups that they belong to. Luhtanen and Crocker (1992) "argue that the emphasis on the more individualistic aspects of selfesteem has offered only a partial view of individuals' self-concepts and social behavior” (p. 303).

Luhtanen and Crocker (1992) conducted a study in which they designed a measure of collective self-esteem. The proposed that there are four possible aspects of collective self-esteem: membership esteem, private collective self-esteem, publiccollective self-esteem, and importance to identity. Membership esteem refers to “individuals’ judgments of how good or worthy they are as members of their social groups” (Luhtanen \& Crocker, 1992, p. 305). Private collective self-esteem refers to “one’s personal judgments of how good one’s social groups are” (Luhtanen \& Crocker, 
1992, p. 305). Public collective self-esteem refers to how the individuals believe that other people evaluate their groups. Finally, the importance to identity dimension refers to the extent to which individuals believe that their group identities are important to their self-concept (Luhtanen \& Crocker, 1992). All four of these aspects of collective selfesteem are measured by the collective self-esteem scale designed by Luhtanen and Crocker (1992).

Previous studies that have examined the relationship between collective selfesteem and other psychological factors indicate that it is related to variables that indicate more positive well-being. A study investigating the influences of collective self-esteem on college students living in residence halls indicates that development of collective selfesteem for college students is related to better adjustment in college (Bettencourt, Charlton, Eubanks, Kernahan, \& Fuller, 1999). Collective self-esteem has also been shown to contribute significantly towards predicting participants' satisfaction with life for South African college students (Mokgatlhe, Bantobestse, Schoeman, \& Johannes, 1998). A study by Mael and Tetrick (1992) indicates that identification with a psychological group or organization is related to job satisfaction, organizational satisfaction, and job involvement. Thus, previous research seems to assert that collective self-esteem is related to better adjustment and satisfaction with life, thus being an important factor to consider when investigating individuals’ self-identity and group identity.

\section{$\underline{\text { Self-Protective Functions of Collective Self-Esteem }}$}

"There is no doubt that prejudice and discrimination have substantial negative social, economic, political, and psychological consequences on members of oppressed or 
stigmatized groups” (Crocker \& Major, 1989, p. 609). Researchers have long hypothesized the effects of discrimination on individual's self-esteem and well-being, predicting lower self-esteem and less satisfaction with life for members of groups who are routinely discriminated against. When referring to stigmatized groups, it is meant "social categories about which others hold negative attitudes, stereotypes, and beliefs, or which, on average, receive disproportionately poor interpersonal or economic outcomes relative to members of the society at large because of discrimination” (Crocker \& Major, 1989, p. 609). It is no wonder that researchers would predict that these groups would have lower self-esteem than those who are not stigmatized. However, studies show that members of stigmatized groups do not necessarily have lower self-esteem than members of the majority, Caucasian, group. For example, studies show that African Americans have levels of self-esteem equal or higher than that of their Caucasian counterparts (Hoelter, 1983). Other reviews of literature show that Chicanos, women, disfigured individuals, developmentally or learning disabled, or homosexual individuals do not have lower self-esteem (Crocker \& Major, 1989). Some researchers in the field have hypothesized that strong ethnic identity and high levels of collective self-esteem would serve a self-protective function for individuals who are members of stigmatized groups (Crocker \& Major, 1989; Roberts, Phinney, Masse, Chen, Robets, \& Romero, 1999; Suzuki-Crumly \& Hyers, 2004; Branscombe, Schmitt, \& Harvey, 1999). In fact, in their study of Jewish early adolescents' ethnic identity, stress and coping, Dubow, Pargament, Boxer, and Tarakeshwar (2000) found that higher scores on measures of Jewish ethnic 
identity were related to more ethnic-related stressors and more ethnic-related coping strategies. The coping strategies included seeking God's direction or support; seeking cultural/social support; and spiritual struggle.

"Components of ethnic identity were related positively to ethnic-related coping. Thus, students more embedded with Judaism have a set of resources for coping to them than do Jewish students who are less identified with their ethnicity. It appears, then, that for those Jewish adolescents who are more ethnically involved, identification with Jewishness or Judaism is a double-edged sword: It creates both stress and the means to solve it” (Dubow, et al., 2000, p. 436).

In their literature review on the relationship between self-esteem and stigma,

Crocker and Major argue that there are three mechanisms by which individuals who are members of a stigmatized group may protect their self-esteem. These include:

a) attributing negative feedback to prejudice against their group;

b) selectively comparing their outcomes with those of members of their own group, and

c) selectively devaluing those attributes on which their group typically fares poorly and valuing those attributes on which their group excels" (Crocker \& Major, 1989, p. 612).

Crocker and Major (1989) argue a method of dealing with bad outcomes by attributing them to discrimination is particularly powerful for members of minority groups because this method can be used when the negative feedback is truly due to prejudice and when it is not. If a member of a stigmatized group attributes negative outcome to internal, stable causes such as lack of ability, self-esteem may suffer. When the negative feedback is attributed to external sources, like prejudice, self-esteem is protected.

Crocker and Major (1989) also argue that if members of disadvantaged groups were to compare themselves to members of the dominant group, their self-evaluations 
would be negative, and thus, self-esteem would suffer. Therefore, these individuals tend to compare themselves to similarly stigmatized groups. Crocker and Major give three reasons for this comparison:

a) as a consequence of segregated environments (a proximity effect)

b) to obtain accurate self-evaluations (a similarity effect), or

c) to avoid unpleasant or painful social comparisons (a self-protective effect) p. 614

Thus, not only do individuals compare themselves to those who are close, and similar, but also to those who are also stigmatized, and thus protect themselves from negative or painful consequences of comparison.

Crocker and Luhtanen (1990) investigated how threats to collective self-esteem. They stated that when faced with threat to positive social identity, or collective selfesteem, “people maintain a positive social identity by identifying or creating favorable comparisons between their own group and outgroup. Thus, individuals will discriminate against or derogate outgroup members relative to the ingroup to create favorable comparisons between the ingroup and outgroup” (p. 60). This type of comparison, as mentioned by Crocker and Major (1989) will have a self-protective effect and result in a positive social identity (Crocker \& Luhtanen, 1990). In this study, the researchers hypothesized that collective self-esteem may moderate the extent to which individuals try to protect or enhance their social identity when it is threatened. "High collective selfesteem people may engage in ingroup-enhancing biases or distortions when faced with a threat to their collective identity, whereas low collective self-esteem subjects may show the absence of such ingroup-enhancing biases” (Crocker \& Luhtanen, 1990, p. 61). 
According to social identity theory, an attempt to restore a positive social identity after a threat may include re-evaluating group attributes from negative to positive. The results of the study by Crocker and Luhtanen (1990) indicated that those with high, but not low, collective self-esteem engage in self-enhancing or ingroup-enhancing social comparisons following a threat to their group. These results support their original hypothesis and the notion that collective self-esteem may help people maintain their positive social identity by modifying their judgments of group attributes.

A study that investigated students' adjustment to college examined students' level of collective self-esteem related to their residence hall membership and how this may influence their academic and social adjustment to college in the first year (Bettencourt et al., 1999). The results of the study indicated that development in collective self-esteem of the participants with campus groups, and specifically their residence hall membership, may contribute to better adjustment to college. Also, increase in collective self-esteem was related to adjustment to college at the end of the first semester as well as increase in adjustment from first semester to second semester of the academic year. The results also indicated that a change in personal self-esteem, quality of students' personal relationships, and the number of extracurricular activities was also related to better adjustment to college for first year students (Bettencourt et al., 1999).

The literature reviewed in this section of the paper dealing with the constructs of subjective well-being, ethnic identity, and collective self-esteem indicates that those who have stronger ethnic identity and more positive collective self-esteem tend to have higher levels of self-esteem, adjustment, coping, and other indicators of subjective well-being. 
There is some evidence that collective self-esteem functions as a self-protective trait for individuals who face discrimination in their daily life. Although no studies have been presented in this review that discuss the relationship between ethnic identity, collective self-esteem and life-satisfaction, it is the hypothesis of the author that life-satisfaction would also be higher for those individuals who report stronger ethnic identity and collective self-esteem. Of course, more research in this area is necessary to be able to support such hypothesis and the information collected in this study may help in that endeavor.

\section{$\underline{\text { Subjective Well-Being }}$}

Psychologists conducting research in positive psychology argue that attention should be paid not only to the absence of negative symptoms in people, but also the presence of positive emotions and cognitions. Subjective well-being refers to a person's cognitive and affective evaluations of his or her life (Diener, Lucas, \& Oishi, 2002). This concept includes such broad factors as pleasant emotions, low levels of negative mood, and high life satisfaction (Diener, Suh, Lucas, \& Smith, 1999). Some research indicates that pleasant affect and unpleasant affect are two independent constructs (although moderately negatively correlated (Diener, Smith, \& Fujita, 1995)) and thus should be measured separately (Bradburn \& Caplovitz, 1965).

Previous research indicates that both demographic and personality variables are related to subjective well-being. Some demographic variables include age, sex, and income. However, the relationship between these variables and subjective well-being is usually small and tends to distinguish between people who are moderately happy and 
those who are very happy (Diener \& Diener, 1996). Neuroticism and extraversion have also been found to be related to subjective well-being. Fujita (1991) found that extraversion correlated with positive affect and neuroticism correlated with negative affect.

Researchers focusing on the relationship between cultural differences and subjective well-being have also found some interesting results. Deiner and Diener (1995) found that self-esteem is less strongly associated with life satisfaction in collectivist cultures than in individualistic cultures. Extraversion has been found to be less strongly associated with pleasant affect in collectivistic cultures (Lucas, Diener, Grob, Suh, \& Shao, 2000).

There are several measures of well-being that have been proposed in the literature. Aside from specific measures, some researchers use the combination of measures of depression, self-esteem, life-satisfaction, psychological symptoms, etc. to measure well-being. Most of these measures are self-report instruments, and some debate exists on how valid they are. Diener et al. (2002) recommend the use of multimethod battery to assess subjective well-being in order to control for problems of self report measures.

Diener, Emmons, Larsen, \& Griffin, 1985) created the Satisfaction with Life Scale. This scale measures a global cognitive assessment of life satisfaction. This 5-item scale has a 7-point Likert response range from strongly disagree (1) to strongly agree (7). Possible scores are 5-35, with higher scores indicating a greater satisfaction with life. 
Reliability for this measure has been reported with internal consistency alpha of .87 for the scale and a two-month test-retest correlation coefficient of .82. A sample item is, "The conditions of my life are excellent."

\section{$\underline{\text { Religiosity and Spirituality }}$}

When discussing the identity and the correlates of identity for a group that is both cultural and religious, it is important to include some discussion of religion and spirituality. is also important to delineate what is meant by religiosity and spirituality. These terms have often been used interchangeably and in the minds of some, are related (Standard, Sandhu, \& Painter, 2000). Religion has been defined to consist of doctrines, ethical codes, practices, rituals, texts, and traditions (Helminiak, 2001).

It is true that for some Jews, religion is not a big part of their lives. However, for others, it is a part of daily life, and self-concept. Bowen, Singal, Eng, Crystal, and Burke (2003) investigated the relationship between Jewish identity and intentions of Jewish women to seek breast cancer screening. This study explored the relationship between Jewish cultural identity and Jewish religious practice. The results indicated that both religious practice and cultural identity were related to various breast cancer screening procedures. However, the two measures of identity predicted different practices, indicating that although there is a relationship between cultural and religious identity, they are different and hold different relationships with health attitudes (Bowen, et al., 2003).

A study by Amyot and Sigelman (1996) using the data from the National Jewish Population Survey examined the relationship of religiosity and social contact with other 
Jews on identification. The results indicated that low levels of religiosity and social contact are associated with a weaker sense of Jewish identification. Another study by Weisskirch (2004) found that religiosity which was measured by the Religious Commitment Inventory (Worthington, Wade, Hight, Ripley, McCullough, Berry, Schmitt, Berry, Bursley, \& O’Connor, 2003) were positively correlated with ethnic identity scores measured by the modified Multigroup Ethnic Identity Measure (Phinney 1992). Also, attendance of synagogue services on Fridays and Saturdays and during Jewish High Holidays was also related to stronger Jewish Ethnic Identity. Self-reports of observance of Jewish religious rituals and practices was also found to be related to stronger Jewish identity (Weisskirch, 2004). Thus it is hypothesized that in this study, measures of religiosity will be related to measures of identification. The relationship between identity and identification is not clear since it is possible that there are Jews that consider themselves primarily cultural or political and thus value their Jewish identity, but may not value religion in their lives.

It is interesting to consider exactly what it is about religiosity that contributes to Jewish identity. The study by Amyot and Sigelman (1996) investigate social contact and religiosity and how these relate to Jewish identity. Weisskirch (2004) investigated the relationship between attendance in synagogue and observance and Jewish Identity. This study will investigate the relationship of both intrinsic religiosity (personal meaning) and extrinsic religiosity (meeting others, making contacts, etc.) and Jewish ethnic identity.

Judaism is a tradition that has valued spirituality and mysticism for centuries. Many Jews would readily consider themselves to be spiritual, as well as religious. 
Therefore, in studying Jewish identity it is important to investigate the relationship of spirituality to other factors of Jewish identity. Spirituality is defined by Purnell (2004) as "the capacity for deep personal integrity, transcendent experiences of reality, and genuine awareness of the interconnected nature of being, which is accompanied by a strong sense of moral purpose whose disciplined expression fosters the optimal development of self and others” (p. 11). Purnell goes further to state that spirituality consists of six dimensions: personal integrity, transcendent truth experiences, awareness of interconnectedness of nature, and moral purpose. All of these dimensions are included in his Global Spirituality Assessment Inventory (GSAI; Purnell, 2004). Personal strength is defined as "coherent knowledge of self, confidence in one's ability to cope with difficulties, and affirmation of the path and meaning of one's life” (Purnell, 2004, p. 32). It is possible that this dimension of spirituality may be related to one's positive ethnic identity. Those who score low on an ethnic identity measure may not have a coherent knowledge of self and thus may score low on this dimension of spirituality. Moral purpose is defined as "an empathic, compassionate concern for others and a commitment to be of service” (Purnell, 2004, p. 32). Service to others is considered to be one of Judaism's main values. Thus, those scoring highly on measures of identity and identification, will probably also score highly on this dimension. Connection to self and others dimension is defined as "a deep awareness of self that allows for full engagement in relationships" (Purnell, 2004, p.33). One aspect of Jewish identity is connectedness to other Jews in the world. It is interesting to investigate if those who identify strongly as Jews will also score highly on this dimension of spirituality. Openness to connection is 
defined as "willingness to attend to oneself and diverse others" (Purnell, 2004, p. 33). Transcendent truth experience is defined as "a direct experience of reality as a broader than sensory perception alone that is accompanied by greater understanding and a sense of peace” (p.33). The transcendent outlook dimension is defined as "an awareness of oneself as a whole and connected to the universe” (p. 33). Purnell states that while all these factors of the GSAI resemble the theoretical definition of spirituality, the do not perform sufficiently in terms of reliability for use as subscales. Thus because some of these dimensions seem to be related to Jewish identity and identification, it is the hypothesis of this study that high scores on the measure of identity and identification will be related with higher scores on GSAI.

A study conducted by Goodman (2002) investigated the differences between Orthodox, Conservative and Reform Jews on measures of collective self-esteem, spirituality, and well-being. The results indicated that Orthodox Jews tend to score higher than Conservative and Reform Jews on 3 of 4 subscales of the collective selfesteem measure (Luhtanen \& Crocker, 1992). Orthodox Jews had higher scores on private self-esteem, membership, and importance to self-concept. The results also indicated that Orthodox Jews scored higher on measures of prayer fulfillment ("feelings of joy and contentment that result from personal encounters with a transcendent reality" (Piedmont, 1999, p. 989)) and universality (oneness of nature and universe). There were no significant differences between members of the Conservative and Reform branches on measures of spirituality. The results of this study also indicated that members of all three branches did not differ on their evaluations of life-satisfaction or the total measure of 
affective psychological well-being, as well as the four subscales of anxiety, depression, somatization, and hostility (Goodman, 2002). These results may indicate that the branch of Judaism that one belongs to is related to spirituality and religiosity, but not well-being. $\underline{\text { Summary }}$

The concepts and studies discussed in this chapter suggest that Jewish identity is an ethnic identity. Thus, certain features that have been found to be associated with other ethnic identities (i.e. self-esteem (Phinney, 1992)) are likely to be also associated with the Jewish identity. So far, no good measure of Jewish identity exists. Current measures are flawed and disagree on the structure of Jewish identity (Cohen, 1977). However, the Multigroup Ethnic Identity Measure designed by Phinney (1992) appears to be a good measure of ethnic identity and may be useful in this study. It is also important to assess the participants' level of Jewish identification and examine the relationship between these concepts. The measure of collective-self-esteem may give some insight into how Jews view themselves as part of the Jewish ethnic group and help to further investigate Jewish identity.

This study will examine the relationship between Jewish Identity and well-being and religiosity and spirituality. Previous studies have suggested that religiosity and spirituality are important aspects of Jewish identity and Jewish well-being (Friedman, et al., 2005; Weisskirch, 2004; Dubow et al., 2003; Bowen, Singal, Eng, Crystal, \& Burke, 2003) In fact, Dubow and colleagues (2000) suggested that religious identification and Jewish identity may be related to utilization of Jewish coping techniques. Also, Bowen, et al. (2003) found that although culture and religion are correlated, each may have 
different relationship with health attitudes. Jewish identity will be measured by instruments focusing on ethnic identity, Jewish identification and collective self-esteem. Well-being will be examined by the measures of self-esteem, depression, and lifesatisfaction. Religiosity will be studies by using a measure of intrinsic and extrinsic religiosity. A measure of global spirituality will also be used in this study.

A nomological network is a graphical representation between the proposed relationships in a study . This representation demonstrates the hypotheses in the study, indicating the proposed relationships between the variables. The top part of a nomological network describes the relationships on a theoretical level, and the bottom part describes the relationships between the actual measures used in the study. The following nomological networks may help further explain the study and may be useful when thinking of the hypotheses described following the nomological networks. 


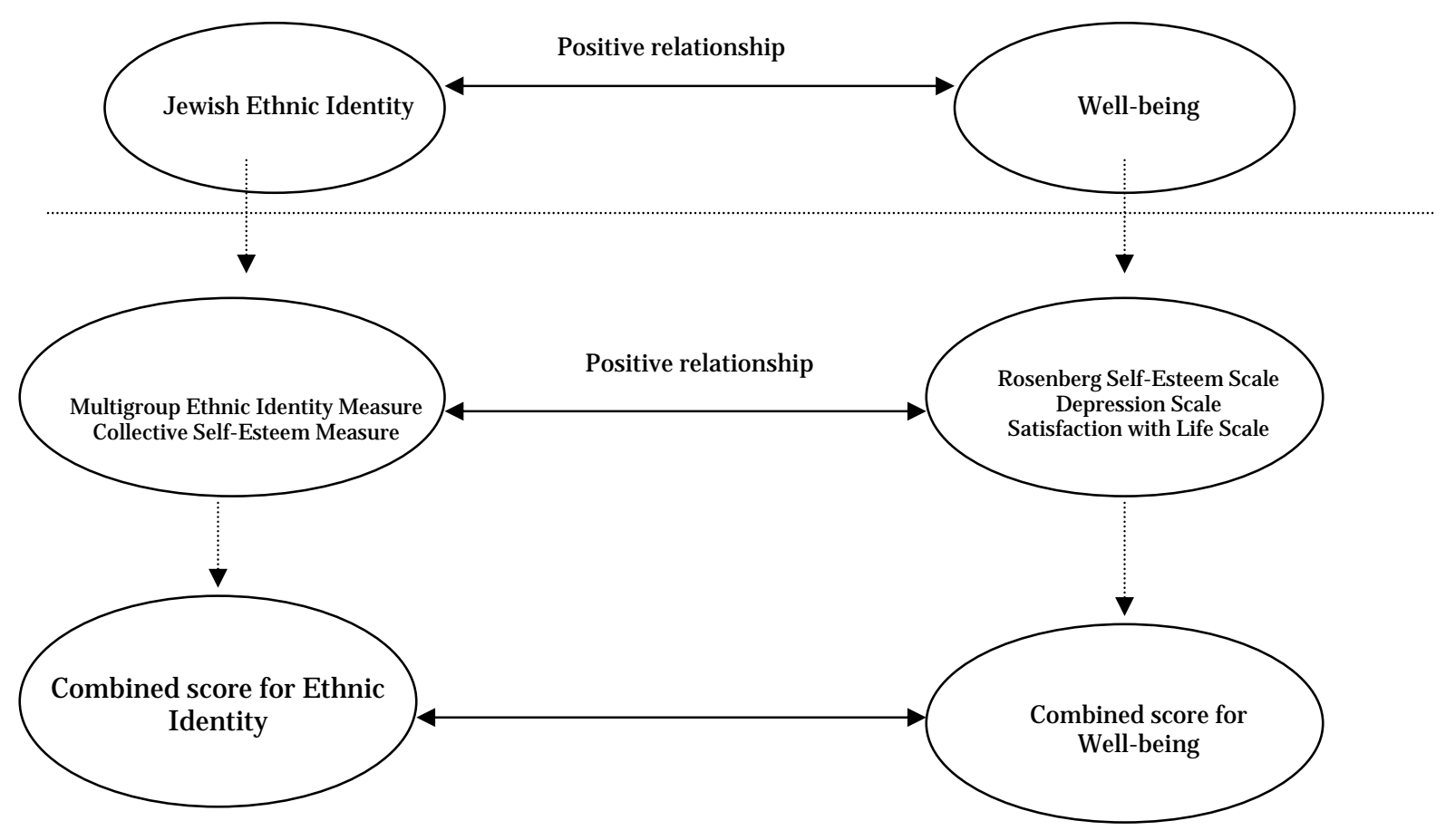

Figure 1: Nomological Network A: Relationship between Jewish ethnic identity and wellbeing - Hypothesis 1 


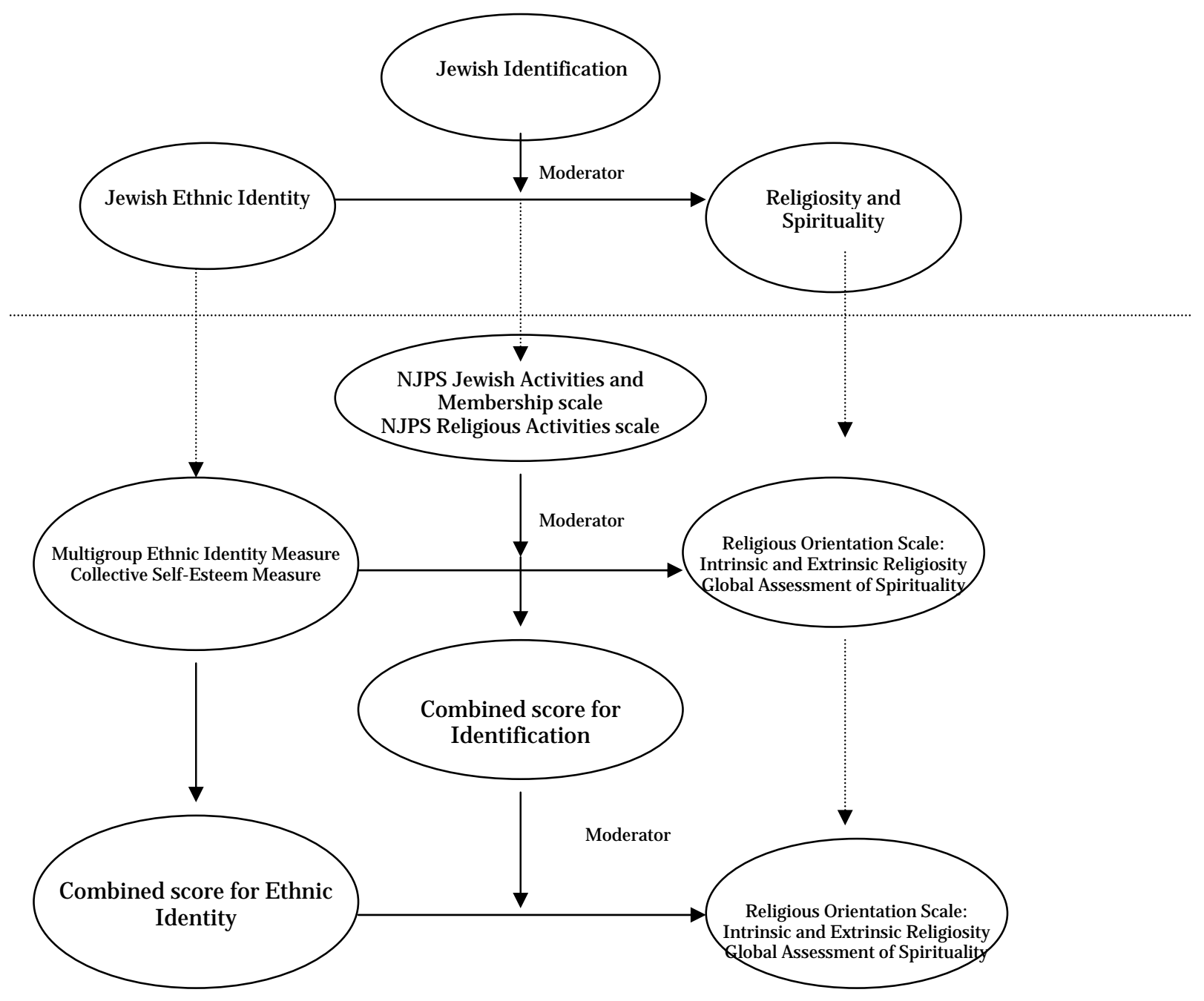

Figure 2: Nomological Network B: Relationship between Jewish ethnic identity and religiosity and spirituality moderated by Jewish identification - Hypothesis 2

The specific hypotheses of this study based on the nomological networks above are listed below:

H1: Previous research (Phinney, 1992) suggests that those individuals who have stronger ethnic identity, tend to have higher self-esteem. Those who have low scores on 
ethnic identity measures may accept the majority view of their ethnic group and thus have lower self-esteem, higher rates of depression, and less satisfaction with life. Research also suggests that one’s group identity may have a protective function against discrimination and thus, stronger Jewish identity and more positive levels of collective self-esteem may be related to higher levels of self-esteem and life satisfaction and lower levels of depression. The prediction of this study is that there is a relationship between Jewish ethnic identity and measures of well-being such that:

a) Jewish Ethnic Identity of the participants will be positively correlated with measures of self-esteem and satisfaction with life.

b) Jewish Ethnic Identity of the participants will be negatively correlated with a measure of depression.

H2: Being Jewish is somewhat different than being a member of another ethnic group because Jews are also a religious group. Religiosity and spirituality are central for many Jews. Jewish identification includes membership in traditionally Jewish organizations and participation in Jewish religious practices and rituals. While Jews who do not identify in these ways may still have strong Jewish ethnic identity and strong religious and spiritual beliefs, these beliefs are likely to be stronger for those who score higher on identification measures because most of the measures of identification revolve around religious, cultural, and spiritual issues. This is supported by the results of a study conducted by Goodman (2002) which indicated that members of the three branches of Judaism (Orthodox, Conservative, and Reform) differed only on measures of spirituality and religiosity and not well-being. Previous studies show that Orthodox Jews tend to have higher levels of identification than Conservative or Reform Jews (Himmelfarb, 
1980). Thus it seems that there may be some relationship between identification and religiosity and spirituality. A hypothesis of this study is that there is a relationship between Jewish ethnic identity and measures of religiosity and spirituality, and this relationship is moderated by the participants' level of identification such that:

a) Jewish Ethnic Identity of the participants will be positively correlated with measures of religiosity and spirituality.

b) Jewish Identification of the participants will be positively correlated with measures of religiosity and spirituality.

c) The interaction of Jewish ethnic identity and Jewish identification will make the relationships described above in a) and b) stronger.

\section{Exploratory Hypotheses}

The following relationships are also investigated in this study. These hypotheses are considered exploratory and are not the main focus of the study.

H3: Because of the nature of Jewish faith, those individuals who find intrinsic value in religiosity should also find their Jewish identity important, it is hypothesized that individuals who have low scores on the ethnic identity measure and high intrinsic religiosity scores, will have low self-esteem, lower satisfaction with life, and higher endorsement of depression items as well as lower overall well-being scores. These relationships may be such because this may imply some kind of an internal conflict.

H4: Many Jews who value their Jewish identity, choose to join Jewish organizations and participate in traditionally Jewish activities. However, there may be some Jew who do not choose to participate in these activities, but still feel that their 
Jewishness is a big part of who they are. The relationship between identification and identity is investigated in this study. It is hypothesized that Jewish identification is related to Jewish identity.

a) For those with high identification scores, there will be a strong, positive correlation with identity scores.

b) For those with low identification scores, the relationship between identification and identity will be unclear, or not as strong, accounting for those who value their Jewishness, but choose not to identify in the traditional ways. 


\title{
CHAPTER 3
}

\author{
METHOD
}

\section{$\underline{\text { Participants }}$}

The participants of this study were 301 individuals (194 female, 103 male, 3 did not indicate) who identified as Jewish, had Jewish upbringing, or who have at least one parent who is Jewish. The participants ranged in age between 15 and 83 . Because this is a study of Jewish adults, the participant whose age is 15 was excluded from the analysis. After removing this participant, the age range is 18 to 83 and the mean age is 34.14 (SD = 15.9). When asked about race, most of the participants indicated being White (92\%), some indicated being of Jewish race (2\%) by writing it in the space provided for other races. The sample also included small numbers of individuals from other races: Black (0.3\%); Asian (0.3\%) Biracial (1\%); Multiracial (2\%); Hispanic (1\%) and other (2\%). The participants also ranged in their level of education, ranging from high school to graduate school, with the biggest group being those who had some graduate school education (40\%) followed by college graduates (27\%), high school graduates (11\%), with the rest (21\%) attending college. The marital status information was also collected and the results indicate that $46 \%$ if the participants are single, $41 \%$ are married, $5 \%$ are 
cohabitating, $3 \%$ are divorced, $2 \%$ are engaged, $2 \%$ are in a serious relationship, and $1 \%$ indicated "other" for their marital status. The participants were also well distributed in their employment status: $42 \%$ employed full-time; $24 \%$ students; $17 \%$ students and employed; 7\% employed part-time; 4\% retired; 3\% unemployed; 2\% stay at home parents; and 1\% other. Of all the participants who indicated their place of residence, 95 were from Ohio, and 206 are from various states in the United States ranging from New York, to Texas, to California.

When asked about religiosity, 54\% indicated considering themselves to be a religious person; 26\% did not consider themselves to be religious; 19\% were not sure; and 2 participants did not answer the questions. Of the participants, 39\% indicated identifying as Conservative; 29\% identified as Reform; 7\% identified as Orthodox; 13\% indicated "other" as their religious affiliation; 11\% indicated "none" and 2 participants did not answer the question. When asked about spirituality, 68\% indicated considering themselves to be spiritual; $13 \%$ stated that they are not spiritual; $19 \%$ indicated not being sure about their spirituality and 1 person did not answer the question.

\section{$\underline{\text { Participant Recruitment }}$}

The participants of this study were recruited from the Research Experience Program (REP) at the Ohio State University and from the Columbus, OH Jewish community, and from the various national Jewish organizations. Of the final 300 participants, 41 came from the introductory psychology pool, and 259 came from the community sample. 
The reason for recruiting participants from both, the college student pool and the community is since this is a study of identity and identification, it is important to have a sample that is diverse on these two dimensions. Since college students are just developing their identity, a sample consisting only of this population would not be representative, nor would it have a good range of identity development. Thus it is important to recruit participants from the community who may be older, or at different stages of their identity development. However, this poses confounding problem. Recruiting from Jewish organizations means that the participants will be those Jews who choose to become members of these organizations, and thus identify as Jews. Therefore, it is important to have a sample of both of these populations.

In order to obtain a sample of Jewish college students, a prescreening measure was administered to all students in the introductory psychology class choosing the experiment option to complete their course requirement (See Appendix 6 for a copy of this questionnaire). The prescreening measure instructed the participants to indicate if they are Jewish, if they had Jewish upbringing, or if their parents are Jewish. If the person indicated in the affirmative to any of these questions, the individual was considered as a possible participant for the study. These individuals were contacted through email and asked to participate in the study for credit that would partially fulfill the requirement for the introductory psychology class (See Appendix 2 for a copy of this email). Those who choose to participate completed the online questionnaires in a 
classroom setting in a computer laboratory on campus. All instruments were completed online, using a secure internet survey service (www.surveymonkey.com). Of the 44 participants who started the study, 41 completed all the measures.

The sample of members of Jewish community was recruited through Jewish organizations, synagogues, and various email listserves. The leadership of these organizations was contacted, requesting them to forward the letter describing the study along with the website for the study to their members (See Appendix 3 for a copy of the community sample recruitment email). The participants of the study were also encouraged to forward the initial email to any other Jewish people they knew who may be interested in participating in this study. The participants were promised to be entered in a drawing for one of three $\$ 50$ prizes. All instruments were completed online, using a secure internet survey service (www.surveymonkey.com). Not all the people who followed the link to the study online actually completed the questionnaires. Of the 391 people who at least looked at the instruments, 260 completed them. This results in a participation rate of $66 \%$ for the community sample.

\section{Instruments}

The instruments of this study included the Multigroup Ethnic Identity Measure, the Collective Self-Esteem Scale, the Rosenberg Self Esteem Scale, the National Jewish Population Survey Identification Scale, the Global Spirituality Assessment Inventory, the Religious Orientation Scale, and the Center for Epidemiological Studies Depression Scale, and a demographic questionnaire (See Appendix 6 for a copy of these materials). 
The measures will be presented in the order that they are listed above. This order was selected because it alternated the content and length of the scales to minimize the effects of fatigue, repetition, and response set.

The Multigroup Ethnic Identity Measure (MEIM; Phinney, 1992). This instrument "provides a means of examining ethnic identity as a general phenomenon that is indicative of young people's degree of identification with their ethnic group, regardless of the unique characteristics of their group” (Phinney, 1992, p. 169). Although this instrument was originally designed for use with adolescents and young adults, it has been used with other populations (Sasson, 2001). Phinney (1992) reported reliability assessed by Cronbach's alpha of .81 for the high school sample, and .90 for the college student sample.

The MEIM consists of 14 items measuring three dimensions of ethnic identity: affirmation and belonging (5 items); ethnic identity achievement (7 items); and ethnic behaviors or practices (2 items) (Phinney 1992). Included in the measure is also a sixitem scale assessing other-group orientation. Phinney (1992) indicates that this is a separate concept from ethnic identity, but it may interact with it as "one's social identity in the larger society” (p. 165). These items are also included to provide balance to the scale with contrast items.

The items of the instrument are rated on a 4-point scale from strongly agree to strongly disagree. Scores are computed by reversing the negatively scored items, summing across items, and obtaining the mean. The scores range from 4 (high ethnic identity) to 1 (low ethnic identity). In the original study, in the cases where questions 
were not answered, means were calculated using the responses given only. A sample item of the scale is "I have spent time trying to find out more about my own ethnic group, such as its history, traditions and customs” (Phinney, 1992).

An investigation of the reliability of this scale indicated that the overall reliability for the 14-item scale was .81 for the high school sample and .90 for the college sample. For the Affirmation and Belonging subscale, reliabilities were .75 and .86 for the high school and college samples, respectively. For the Ethnic Identity Achievement subscale the reliabilities were .69 and .80 for the high school and college samples, respectively. For the Ethnic Behaviors subscale, reliability was not computed since this subscale consists of only two items. Phinney (1992) indicates that separate analyses showed that this scale increased the overall reliability of the measure. For the Other-Group Orientation subscale, the reliability statistics were .71 and .74 for the high school and college samples respectively. The reliabilities for the college sample were consistently higher than those for the high school sample (Phinney, 1992).

For the purposes of this study, the terms "my own ethnic group," or "my ethnic group” was replaced by such terms as “Jewish ethnic group,” or “Jewish group,” or "Jewish people" since this is the only population studied. The participants were not given a choice of ethnic group to indicate and the directions for the scale were be revised to reflect these changes. The Cronbach's alpha for the sample in the current study for this instrument is .84 . 
National Jewish Population Survey Identification Scale (NJPS-IS; United Jewish

Communities, 2003) This instrument consists of questions dealing with identification included in the National Jewish Population Survey 2001-2002. Since the original survey was conducted over the phone, the items needed to be modified to fit the paper and pencil version. This new version of the survey only includes items dealing with identity and identification. This measure consists of 52 items, with answer choices ranging from yes (1) to don't know/don't remember (3) for the first section (questions 1-16). The answer choices range from never (1) to always (4) for the second section (questions 17-28). The answer choices range from strongly disagree (1) to strongly agree (5) for the third section (questions 29-50). Questions 51 and 52 ask for less structured responses and are used for informational purposes only. Sample items from this scale are "In the past year, I have read a Jewish newspaper, magazine, or other publication” (section 1); “How often do you light Sabbath candles on Friday night?” (section 2); and “I try to observe most of the practices and rituals of Judaism” (section 3). The Cronbach's alpha for this scale in this study is 0.95 .

The overall measure consists of two subscales and other, informational items. These subscales were used for analysis in this study because the different sections of this measure use different response scales. The Jewish Activity and Membership scale consists of 13 items, with scores ranging from 0 to 26. The Cronbach's alpha for this scale is 0.79. A sample item from this scale is "In the past year, I have read a Jewish newspaper, magazine, or other publication.” The Religious Practices scale consists of 16 
items, with scores ranging from 16 to 64 . The Cronbach's alpha for this scale is 0.87 . A sample item from this scale is "How often do you light Sabbath candles on Friday night?" Collective Self-Esteem Scale, Race Specific Version (CSE - R ; Luhtanen \& Crocker, 1992). This scale measures individuals' social identity level on the basis of membership in a group. This measure consists of four subscales: membership esteem, private collective self-esteem, public-collective self-esteem, and importance to identity. Membership esteem refers to “individuals' judgments of how good or worthy they are as members of their social groups” (Luhtanen \& Crocker, 1992, p. 305). Private collective self-esteem refers to "one’s personal judgments of how good one’s social groups are” (Luhtanen \& Crocker, 1992, p. 305). Public collective self-esteem refers to how the individuals believe that other people evaluate their groups. Finally, the importance to identity dimension refers to the extent to which individuals believe that their group identities are important to their self-concept (Luhtanen \& Crocker, 1992). The measure consists of 16 items, with responses ranging from strongly disagree (1) to strongly agree (7). A sample item from this instrument is "I am a worthy member of my ethnic group." Reliability analyses indicated that the overall scale and the subscales are internally consistent with alphas ranging from .73 for the membership subscale to alpha of .80 for the public subscale. The overall alpha was .85 (Luhtanen and Crocker, 1992). The test-retest reliability (6-week) were $r=.68$ for the entire scale. The correlations for the subscales ranged from $r=.58$ for the membership subscale to $r=.68$ for the identity subscale. The overall Cronbach's alpha for this scale in this study is 0.88 . 
Global Spirituality Assessment Inventory (Purnell, 2004). This inventory measures individual's level of global spirituality including: personal growth; moral purpose; connection to self and others; openness to connection; transcendent truth experience; and transcendent outlook. This measure consists of 32 items, scored on a 5point Likert scale ranging from strongly disagree (1) to strongly agree (5). The coefficient alpha reliability for this inventory was reported to be .87. For this study, a revised version of this measure was used. The designer of the measure (Purnell) added questions to the original version in order to increase reliability and strengthen the factors. The total number of items for this revised version is 65 . In this study, the coefficient alpha for the revised version of GSAI is 0.91. A sample item from this measure is "I am part of something greater than myself.”

Religious Orientation Scale (ROS; Allport \& Ross, 1967). This is a widely used measure of intrinsic and extrinsic orientation toward religion, referring to personal meaning and social, or status, significance significantly. The scale in its original form includes references to bible study and church, which restricts its interpretability primarily for Christian respondents (Burris, 1999). Thus, for use with Jewish participants, such references will be modified to appropriate concepts. The internal consistency Cronbach’s alphas of the two subscales were reported in the mid .80 's for the intrinsic subscale and mid .70's for the extrinsic subscale (see Burris, 1999 for a review). In this study, the alphas are 0.79 for the intrinsic subscale and 0.76 for the extrinsic subscale. The responses are provided using a Likert scale from strongly disagree (1) to strongly agree 
(5). Sample items of the scale include "The primary purpose of prayer is to gain relief and protection," "I try hard to carry my religion over into all my other dealings in life." Rosenberg Self-Esteem Scale (RSES; Rosenberg, 1965). This instrument is a measure of global feelings of self-worth or self-acceptance. It consists of 10 items scored on a 4-point Likert scale, with responses ranging from strongly disagree (0) to strongly agree (3). Scores range from 0-30, and higher scores indicate higher levels of selfesteem. An internal consistency alpha of .88 and a test-retest coefficient of .82 have been reported for this scale (Fleming \& Courtney, 1984). In this study, the Cronbach’s alpha is 0.90 . A sample item is, "I feel that I have a number of good qualities."

Center for Epidemiological Studies Depression Scale (CES-D; Radloff, 1977)

This instrument measures depression with features including a) depressed mood, b) feelings of guilt and worthlessness, c) feelings of helplessness and hopelessness, d)psychomotor retardation, e) loss of appetite, and f) sleep disturbance. The scale was developed by selecting a pool of items from previously validated depression scales. This 20-item scale instructs respondents to indicate how often they have experienced feelings or exhibited behaviors reflected in each item during the past week. Responses are given on a 4-point Likert scale ranging from rarely or none of the time (0) to most or all of the time (3). Higher scores indicate more depression symptomalogy. Internal consistency alpha for this scale has been reported at .85 , with test-retest ranging from .45 to .70 . In this study, the Cronbach's alpha is 0.90 . The scale was normed on various age groups, races, both genders, and three levels of education. Coefficient alphas for all subgroups were .80 or higher. A sample item is, "I felt that everything I did was an effort." 
Satisfaction with Life Scale (SLS; Deiner, Emmons, Larsen, \& Griffen, 1985).

This scale measures a global cognitive assessment of life satisfaction. This 5-item scale has a 7-point Likert response range from strongly disagree (1) to strongly agree (7).

Possible scores are 5-35, with higher scores indicating a greater satisfaction with life. Reliability for this measure has been reported with internal consistency alpha of .87 for the scale and a two-month test-retest correlation coefficient of .82. The Cronbach’s alpha for this scale for this study is 0.89. A sample item is, “The conditions of my life are excellent."

Demographic questionnaire . This instrument, designed specifically for this study, consists of 10 questions, instructing the respondent to indicate his or her age, gender, race, marital status, education level, place of birth, employment status, religious affiliation, and religiosity and spirituality. No identifying data was requested 


\section{CHAPTER 4}

\section{RESULTS}

This section of the document will present the statistical analysis of the data in this study. Descriptive statistics will be presented for the scales used in this study. The two subject samples used in this study will be compared to determine whether or not they can be analyzed as one sample or if separate analysis needs to be performed. The data will also be compared across genders, religious affiliation and state of residence. To evaluate the hypotheses of this study, correlation analysis, regression analysis, and t-tests will be performed. Interpretations of the findings will be described in the next section.

\section{Descriptive Statistics}

Descriptive statistics for all variables were computed and are presented in Table 1. This table presents the mean, standard deviation, minimum and maximum for each variable. The subscales of the various measures were also calculated and the descriptive statistics are also presented for each of these. From this table, it can be seen that the scores on most of the variables are spread along a wide range with a mean near the actual mid-points for the scales. The means for ethnic identity (MEIM) and collective 
self-esteem (CSER) were above the mid-point, indicating that the participants in this sample may on average, have stronger ethnic identity and collective self-esteem.

\section{Sample Comparison}

The participants in this study came from two different samples. The first was obtained from recruitment of members of the community in Ohio and across the United States. The second sample was obtained from recruitment of participants from the Research Experience Program (REP) subject pool at The Ohio State University. Before any analysis can be done, it is important to compare these samples across the variables in this study to see if they are similar, or if they are different. An independent samples t-test was performed to compare the samples. The means for each scale and subscale, as well as the t-score are presented in Table 2. For most of the variables, there was a significant difference in the mean score for the REP and the Community samples. For example, participants in the REP sample were younger than the participants in the community sample with the mean age of 18.98 for the REP sample and 36.54 for the community samples. Also, the participants in the community sample indicated higher levels of Jewish activities and membership (17.59 for Community and 11.76 for REP) and for religious practice (50.22 for Community and 42.66 for REP). The participants of the Community sample also had stronger ethnic identity scores and collective self-esteem scores than those in the REP sample (MEIM 3.50, CSER 5.93 for community; MEIM 2.94, CSER 4.98 for REP). The participants in the Community sample also had higher mean scores for spirituality (258.65 for community, 243.79 for REP), intrinsic religiosity (3.18 for community, and 2.70 for REP), and lower scores for extrinsic religiosity (2.62 
for community, and 3.08 for REP). Because such differences exist, for the rest of the analysis these two samples will be treated separately, and all results will be presented individually for each sample.

The other sample difference that could potentially confound the results in this study is the place of residence of the participants. A large portion of the samples comes from Ohio (all of the REP sample; and $21 \%$ or 54 participants in the Community sample). Since such a large group of participants comes from the same geographic location, it is important to investigate if this group is somehow different from the rest of the sample. The means of each of the variables were compared for the Ohio sample and the Other U.S. state sample. Since the residents of other U.S. states were only part of the Community sample, that is the only data presented. The results of the t-test indicate that the samples are only different in age $(\mathrm{p}<.05)$, and CSER overall score $(\mathrm{p}<.05)$. The mean age for the Ohio sample was $41.38(\mathrm{SD}=17.34)$ and it was $35.00(\mathrm{SD}=14.93)$ for the other states sample. The mean overall score on CSER for the Ohio sample was $6.11(\mathrm{SD}=.45)$ and $5.88(\mathrm{SD}=.75)$ for the other states sample. This indicates that although the Ohio sample and the other states sample differ on measure of collective self-esteem and on age, they are overall, similar and thus can be treated as one sample.

The participants were also compared by gender. The variables on which the gender differences as determined by an independent samples t-test are presented in Table 3 for the REP sample and Table 4 for the Community sample. For the REP sample, the genders differed only on ROS Extrinsic Religiosity Subscale $(\mathrm{p}<.01)$. On the ROS 
Extrinsic Religiosity subscale, men on average, scored higher than women (4.41, $\mathrm{SD}=0.60 ; 2.82, \mathrm{SD}=.60$; respectively) indicating that men might be more likely to engage in religious activities for some extrinsic purpose.

For the Community sample, the genders differed in age ( $\mathrm{p}<0.01$;males 41.04 , $\mathrm{SD}=18.40$; females $34.20, \mathrm{SD}=13.74)$ and the global spirituality (GSAI) score $(\mathrm{p}<.01$; males 252.45, $\mathrm{SD}=23.76$; females 261.96, $\mathrm{SD}=19.58$ ). In this sample, the men tended to be older than the women. The women scored higher on all the subscales of the GSAI and had a higher overall GSAI score, indicating that women in this sample may be more spiritual as measured by the Global Spirituality Assessment Inventory across various dimensions. This is a unique finding to this study. In his scale development, Purnell (2004) did not find any gender differences for males and females on the GSAI. However, since men and women were similar in their scores on most of the scales in this study, they were not treated as different samples.

\section{Ethnic Identity, Well-Being, and Identification Scores}

To help with analysis of data and make interpretations easier, composite scores for Ethnic Identity, Well-Being, and Identification were computed using the principle components analysis. The Ethnic Identity score was computed by using the total scores on the MEIM and the CSER. The new Ethnic Identity score accounts for $82.17 \%$ of variance as measured by the individual scales. The Well-Being score was computed by using the total scores on the SLS and RSES and a reversed total score on the CES-D scale. The score on the CES-D scale needed to be reversed because on this scale, initially, higher scores indicated higher levels of depression and thus less well-being. 
The new Well-Being score accounts for $74.04 \%$ of variance as measured by the individual scales. The Identification score was computed by using the totals of the NJPS Jewish Activities and Membership scale and NJPS Jewish Religious Practice scale. The new Identification score accounts for $82.17 \%$ of the variance as measured by the individual scales. These composite scales were used in all subsequent analyses and are referred to as the Ethnic Identity factor score, Well-being factor score, and the Identification factor score.

\section{$\underline{\text { Religious Affiliation }}$}

Previous studies indicate that participants indicating different Jewish religious affiliations (Orthodox, Conservative, Reform, etc) differ in their scores on measures of ethnic identity and Jewish identification with Orthodox Jews having the highest scores(Weisskirch, 1004). This finding was investigated in this study by using one-way ANOVA analysis. The results indicate that there were significant differences for levels of MEIM ethnic identity $(\mathrm{p}<.01)$, collective self-esteem $(\mathrm{p}<.01)$, intrinsic religiosity $(\mathrm{p}<.01)$, NJPS Jewish activities and membership $(\mathrm{p}<.01)$, Jewish religious practice $(\mathrm{p}<.01)$, Jewish ethnic identity factor $(\mathrm{p}<.01)$, and identification factor $(\mathrm{p}<.01)$ across various Jewish religious affiliations for the community sample. The means for each of these variables are presented by religious affiliation in Table 5 . On each of these measures, Orthodox individuals score tend to score highest, followed by Conservative individuals, followed by Reform participants, followed by those who indicated "other" 
and "none" as their religious affiliation. For the REP sample, because the sample size is small ( $\mathrm{N}=41)$ and there was only one participant who indicated being Orthodox the differences between religious affiliations for this sample were not calculated.

Post hoc Tukey test indicates that for the MEIM ethnic identity scores, Orthodox, Conservative, and Reform individuals, and those indicating 'other” as their religious affiliation had significantly higher scores than those indicating having no religious affiliation ( $\mathrm{p}<.01$ for all the comparisons). The other differences in the MEIM scores were not found to be significant. The post hoc Tukey test indicates that for CSER collective self-esteem scores, Orthodox, Conservative, and Reform individuals, and those indicating "other" for their religious affiliation had significantly higher scores than those indicating no religious affiliation ( $\mathrm{p}<.01$ for all the comparisons). The same pattern of results was found for the Jewish Ethnic Identity factor score $(\mathrm{p}<.01)$.

Post hoc Tuckey test indicates that for intrinsic religiosity, Orthodox individuals had scores that were significantly higher than Conservative individuals $(\mathrm{p}<.01)$, Reform individuals $(\mathrm{p}<.01)$, those indicating "other as their religious affiliation $(\mathrm{p}<.01)$, and those indicating "none” as their religious affiliation $(\mathrm{p}<.01)$. Conservative individuals had significantly higher scores than those indicating "none” as their religious affiliation $(\mathrm{p}<.01)$

Post hoc Tuckey test indicates that for Jewish Activities and Membership, Orthodox, Conservative, and Reform individuals as well as those indicating "other” as their religious affiliation had significantly higher scores than those indicating "none” as their religious affiliation ( $\mathrm{p}<.01$ for all comparisons). For Jewish Religious Practice, 
Orthodox individuals had significantly higher scores than Conservative individuals $(\mathrm{p}<.01)$, Reform individuals $(\mathrm{p}<.01)$, those indicating "other" as their religious affiliation $(\mathrm{p}<.01)$ and those indicating having no religious affiliation $(\mathrm{p}<.01)$. Conservative individuals had significantly higher scores than Reform individuals $(\mathrm{p}<.01)$, those indicating "other" $(\mathrm{p}<.01)$ and those indicating "none” $(\mathrm{p}<.01)$. Reform individuals had significantly higher scores than those reporting "none" as their religious affiliation, but not those indicating "other" as their religious affiliation.

For the Identification factor, the difference in scores for Orthodox individuals and Conservative individuals was marginally significant ( $<<.052)$. Orthodox individuals had scores that were significantly higher than Reform individuals ( $p<.01)$, those indicating "other" as their religious affiliation $(\mathrm{p}<.01)$, and those indicating having no religious affiliation $(\mathrm{p}<.01)$. Conservative individuals had significantly higher scores than Reform individuals $(\mathrm{p}<.01)$, those indicating "other" $(\mathrm{p}<.01)$ and those indicating "none” $(\mathrm{p}<.01)$. Reform individuals had significantly higher scores than those reporting "none" as their religious affiliation, but not those indicating "other” as their religious affiliation.

The participants of the study were also asked if they consider themselves religious. The results indicate that for the REP sample, 31.7\% ( $\mathrm{N}=13)$ of the participants indicated that they considered themselves to be religious; 36.6\% ( $\mathrm{N}=15)$ did not consider themselves religious; and 31.7\% ( $\mathrm{N}=13$ ) were unsure. For the community sample, 57.9\% ( $N=150$ ) of the participants indicated that they considered themselves to be religious; 23.9\% ( $\mathrm{N}=62)$ did not consider themselves religious; and 17.4\% ( $\mathrm{N}=45)$ were unsure (2 participants did not answer this question). Analysis of variance was performed to 
investigate whether those who thought of themselves as religious or not differed on measures of intrinsic religiosity, extrinsic religiosity, and Jewish activities and membership and Jewish religious practices. The ANOVA indicates that for the REP sample, the difference on intrinsic religiosity was marginally significant $(\mathrm{F}=2.856, \mathrm{p}=.07)$ and the difference on the Jewish Religious Practices scale of NJPS was significant $(\mathrm{F}=3.42, \mathrm{p}<.05)$. Those who considered themselves to be religious, had a mean score of $2.97(\mathrm{SD}=.42)$ for intrinsic religiosity and a mean score of $46.83(\mathrm{SD}=7.21)$ on Jewish religious practices scale. Those who were not sure about their religiosity had a mean score of $2.65(\mathrm{SD}=.64)$ for intrinsic religiosity and a mean score of $42.62(\mathrm{SD}=8.45)$ on Jewish religious practices scale. Those who did not consider themselves to be religious had a mean score of 2.49 (SD=.52) for intrinsic religiosity and a mean score of 39.09 $(\mathrm{SD}=7.75)$ on Jewish religious practices scale.

Post hoc Tukey test indicates that for the REP sample, difference in scores on intrinsic religiosity were marginally significant for those who considered themselves religious and those who did not consider themselves religious $(\mathrm{p}=.059)$. For the Jewish Religious Practices scale, those who considered themselves religious had significantly higher scores than those who did not $(\mathrm{p}<.05)$.

The ANOVA indicates that for the community sample, the difference on intrinsic religiosity was significant $(\mathrm{F}=32.13, \mathrm{p}<.01)$ and the difference on the Jewish Religious Practices scale of NJPS was significant $(\mathrm{F}=89.46, \mathrm{p}<.01)$. Those who considered themselves to be religious, had a mean score of $3.57(\mathrm{SD}=.60)$ for intrinsic religiosity and a mean score of $54.82(\mathrm{SD}=5.74)$ on Jewish religious practices scale. Those who were 
not sure about their religiosity had a mean score of $2.93(\mathrm{SD}=.55)$ for intrinsic religiosity and a mean score of $47.00(\mathrm{SD}=6.29)$ on Jewish religious practices scale. Those who did not consider themselves to be religious had a mean score of $2.34(\mathrm{SD}=.81)$ for intrinsic religiosity and a mean score of $41.47(\mathrm{SD}=9.28)$ on Jewish religious practices scale.

Post hoc Tuckey test indicates that for the community sample, those who considered themselves religious had significantly higher scores on intrinsic religiosity than those who did not $(\mathrm{p}<.01)$ and those who were unsure of their religiosity $(\mathrm{p}<.01)$. Those who were unsure of their religiosity had significantly higher scores on intrinsic religiosity than those who did not consider themselves to be religious $(\mathrm{p}<.01)$ For the Jewish religious practices scale, those who considered themselves religious, had significantly higher scores than those who did not consider themselves religious $(\mathrm{p}<.01)$ and those who were unsure of their religiosity $(\mathrm{p}<.01)$. Those who were unsure of their religiosity had significantly higher scores on Jewish religious practices scale than those who did not consider themselves to be religious $(\mathrm{p}<.01)$.

For the community sample, the group of participants who indicated that they considered themselves to be religious, had a greater percentage of individuals identifying as Orthodox Jews (12.7\%) than those who did not consider themselves religious (0.0\%) and those who were unsure (2.2\%). There was also a higher percentage of Conservative group for those who considered themselves to be religious (44.7\%) than those who did not consider themselves religious (35.5\%) and those who were unsure (33.3\%). The percentage of Reform Jews was higher for those who did not considered themselves to be religious (29.0\%) than for those who did consider themselves to be religious (26.7\%) and 
those who did not consider themselves to be religious (24.4\%). Those who did not consider themselves to be religious also had a higher percentage of individuals stating that they did not have a Jewish religious affiliation (22.6\%) than those who were unsure (15.6\%) and those who indicated being religious (4.0\%).

The participants were also asked to indicate if they consider themselves to be spiritual. For the REP sample, 53.7\% $(\mathrm{N}=22)$ indicated that they considered themselves to be a spiritual person; $19.5 \%(\mathrm{~N}=8)$ indicated that they did not consider themselves to be spiritual; and $26.8 \%(\mathrm{~N}=11)$ were not sure. For the community sample, $70.3 \%$ $(\mathrm{N}=182)$ indicated that they considered themselves to be a spiritual person; $12.0 \%$ $(\mathrm{N}=31)$ indicated that they did not consider themselves to be spiritual; and 17.4\% $(\mathrm{N}=45)$ were not sure.

Analysis of variance was performed to investigate whether those who thought of to be spiritual or not differed on the scores of global spirituality (GSAI). For the REP sample, the no significant difference was found. For the community sample, the differences on the GSAI scores were significant $(\mathrm{F}=30.71, \mathrm{p}<.01)$. Those who considered themselves to be spiritual had a mean score of 264.71 (SD=18.82) on the GSAI. Those who were not sure about whether or not they considered themselves to be spiritual had a mean score of $244.86(S D=20.95)$ on the GSAI. Those who did not consider themselves to be spiritual had a mean score of 242.69 (SD=20.50) on the GSAI. Post hoc Tuckey test indicated that for the community sample, those who considered themselves to be spiritual, had significantly higher scores on the GSAI than those who did not $(\mathrm{p}<.01)$ and those who were unsure $(\mathrm{p}<.01)$. 


\section{$\underline{\text { Correlations }}$}

To investigate the relationship among the variables in this study, correlation analysis was performed. Table 6 presents the correlations for the REP sample and the correlations for the Community sample. The results indicate that for the REP sample, MEIM scores were positively correlated with self esteem $(r=.47, \mathrm{p}<.01)$ and negatively correlated with depression ( $r=-.52, \mathrm{p}<.01$ ), and positively correlated with the Well-Being factor $(r=.49, \mathrm{p}<.01)$. The MEIM scores for this group were not significantly correlated with the Satisfaction with Life scale. The CSER scores were positively correlated with self-esteem $(r=.48, \mathrm{p}<.01)$, negatively correlated with depression $(r=-.47, \mathrm{p}<.01)$, and positively correlated with the Well-Being factor $(r=.48, \mathrm{p}<.01)$. The CSER scores were not significantly correlated with the Satisfaction with Life scale. The Jewish Ethnic Identity factor was positively correlated with the Well-Being factor $(r=.55, \mathrm{p}<.01)$ supporting Hypothesis 1 of this study for this sample.

For the community sample, several of the same relationships were seen. The MEIM scores were positively correlated with Satisfaction with Life $(r=.18, \mathrm{p}<.01)$ and self-esteem $(r=.17, \mathrm{p}<.01)$ and negatively correlated with depression $(r=-.20, \mathrm{p}<.01)$. The MEIM scores were also positively correlated with the Well-Being factor $(r=.22$, $\mathrm{p}<.01)$. The CSER scores were positively correlated with satisfaction with life $(r=.23$, $\mathrm{p}<.01)$ and self-esteem $(r=.21, \mathrm{p}<.01)$ and negatively correlated with depression $\quad(r=-$ $.18, \mathrm{p}<.01)$. The CSER scores were also significantly correlated with the Well-Being 
factor $(r=.24, \mathrm{p}<.01)$. The Jewish Ethnic Identity factor was positively correlated with the Well-Being factor $(r=.27, \mathrm{p}<.01)$ supporting Hypothesis 1 of this study for this sample.

Jewish Ethnic Identity factor was also related to Global Spirituality $(r=.25, \mathrm{p}<.01$ for the community sample and $r=.52, \mathrm{p}<.01$ for the REP sample), Intrinsic Religiosity ( $r=.44, \mathrm{p}<.01$ for the community sample, not significant for REP sample), and Extrinsic Religiosity ( $r=.12, \mathrm{p}<.05$ for the community sample, not significant for the REP sample).

\section{$\underline{\text { Regression Analysis }}$}

In order to test Hypothesis 2 of this study, that Jewish Identification moderates the relationship between Jewish Ethnic Identity and Religiosity and Spirituality, these variables were entered into hierarchical regression models. For the investigation of the relationship between Jewish ethnic identity, identification, and spirituality, a separate regression model was computed for the community sample and for the REP sample. The order of the variables entered into the hierarchical regression was: Jewish Ethnic Identity factor, Identification factor, and the interaction between with GSAI scores as a dependent variable. The order was decided based on the hypotheses presented and the nomological network discussed earlier in this paper. The hypothesis was that ethnic identity is related to religiosity and spirituality and that this relationship is moderated by identification.

Hierarchical regression analysis was also used to investigate the hypothesis that Jewish Identification moderates the relationship between Jewish ethnic identity and religiosity (intrinsic and extrinsic). This analysis was only performed for the community sample, because for the REP sample, no relationship was found between ethnic identity 
and intrinsic and extrinsic religiosity. The order of the variables entered into the regression was: Jewish Ethnic Identity factor, Identification factor, and the interaction between these with intrinsic religiosity as a dependent variable and Jewish Ethnic Identity factor, Identification factor, and the interaction between these with extrinsic religiosity as a dependent variable.

The results of the analysis for the community sample are presented in Table 7and the results for the REP sample are presented in Table 8.

The results indicate that Identification moderates the relationship between Jewish ethnic identity and Global spirituality for the community sample $(\mathrm{p}<.01)$. This moderation is of the type that as identity scores go up, so do spirituality scores and for those who score higher on identification, the relationship is stronger. There was no moderation effect between ethnic identity and spirituality found for identification in the REP sample.

The results of the regression also indicate that identification moderates the relationship between Jewish ethnic identity and extrinsic religiosity $(\mathrm{p}<.018)$, but not intrinsic religiosity for the community sample. The moderation is of type that as identity scores go up, so do extrinsic religiosity scores and for those who score higher on identification, the relationship is stronger.

Thus, the regression analysis indicates that Hypothesis 2 of this study was partially supported. 


\section{Exploratory Hypothesis 3}

An exploratory hypothesis of this study was that those participants who had low Jewish ethnic identity scores and high intrinsic religiosity scores would have lower selfesteem scores, lower satisfaction with life scores, and higher depression scores than the rest of the sample. This hypothesis was investigated by splitting the community sample into two groups. Group 1 consisted of those who had scores on the Jewish ethnic identity factor below the mean (.169) and intrinsic religiosity scores above the mean (3.178). Group 2 consisted of participants with Jewish ethnic identity scores above the mean and intrinsic religiosity below the mean. The mean scores the well-being factor were compared for these groups using a t-test. For Group $1(\mathrm{~N}=36)$ the well-being factor mean score was -.555 (SD=.962). For Group $2(\mathrm{~N}=223)$ the well-being factor mean score was .083 $(\mathrm{SD}=.984)$. The t-test indicated that these scores are significantly different $(\mathrm{t}=3.68, \mathrm{p}<.01)$. This finding supports Hypothesis 3 of this study.

This hypothesis was also investigated for the REP sample by splitting the sample into two groups. Group 1 consisted of those who had scores on the Jewish ethnic identity factor below the mean (-.107) and intrinsic religiosity scores above the mean (2.70). Group 2 consisted of participants with Jewish ethnic identity scores above the mean and intrinsic religiosity below the mean. The mean scores the well-being factor were compared for these groups using a t-test. For Group $1(\mathrm{~N}=9)$ the well-being factor mean score was -.897 (SD=.714). For Group $2(\mathrm{~N}=32)$ the well-being factor mean score was 
$.350(\mathrm{SD}=.829)$. The $\mathrm{t}$-test indicated that these scores are significantly different $(\mathrm{t}=4.46$, $\mathrm{p}<.01$ ). This finding supports Hypothesis 3 of this study; however, interpretations should be made cautiously since Group 1 only had 9 participants.

\section{Exploratory Hypothesis 4}

An exploratory hypothesis of this study was that the relationship between Jewish Ethnic Identity and Identification would be different for those who are high on identification scores and those who are low on identification scores. It was predicted that there would be a strong positive relationship between Identity and Identification for the high identifying group and that this relationship would be unclear or weaker for the low identifying group. This hypothesis was explored by splitting the community sample by identification scores. Those who had identification factor scores below the mean (.141) were placed in the "Low Identifiers" group and those with identification factor scores above the mean were placed in the "High Identifiers" group. The correlations between the Ethnic Identity factor and Identification factor were computed for each of these groups. For the High Identifiers ( $\mathrm{N}=146)$, the correlation between ethnic identity factor and identification factor was significant $(r=.198, \mathrm{p}<.05)$, for Low Identifiers ( $\mathrm{N}=113)$, the correlation was also significant $(r=.648, \mathrm{p}<.01)$. The difference between these correlations was tested using a $z$-test $(z=4.52)$ and this difference was found to be significant $(\mathrm{p}<.01)$. This indicates that the relationship between Jewish ethnic identity and Jewish Identification does differ for the high and low identifiers, such that for low identifiers, the relationship is stronger than for high identifiers. This finding is not the predicted finding of Hypothesis 4. In fact, it is the opposite of the prediction. 
This analysis was also preformed for the REP sample. Those who had identification factor scores below the mean (-.891) were placed in the "Low Identifiers" group and those with identification factor scores above the mean were placed in the "High Identifiers” group. The correlations between the Ethnic Identity factor and Identification factor were computed for each of these groups. For the High Identifiers $(\mathrm{N}=8)$, the correlation between ethnic identity factor and identification factor was not significant ( $r=.194, \mathrm{p}=.645)$. For the Low Identifiers $(\mathrm{N}=33)$, the correlation between Jewish Ethnic Identity factor and Jewish Identification factor was significant $(r=.638$, $\mathrm{p}<.01$ ). These findings indicate that the relationship between Jewish ethnic identity and Jewish identification does differ for the high and low identifiers, such that for low identifiers, the relationship is stronger than for high identifiers. This finding, just like for the community sample, is not the predicted finding of Hypothesis 4, but the opposite of the original prediction.

\section{Being Jewish in America Means:}

The participants of the study were asked to indicate if they thought that being a Jew in America meant being part a religious group, a cultural group, an ethnic group, a nationality, or something else. The participants could select more than one choice. The results indicate that $82.9 \%$ of the REP sample and $88.0 \%$ of the community selected religious group; $53.7 \%$ of the REP sample and $78 \%$ of the community sample selected ethnic group; $58.5 \%$ of the REP sample and $90.3 \%$ of the community sample selected cultural group; $29.3 \%$ of the REP sample and $31.3 \%$ of the community sample selected nationality; and $0.0 \%$ of the REP sample and $8.5 \%$ of the community sample selected 
“other” with some of these individuals writing in "a people” as an alternative. These varying percentages and high endorsement of religious group, ethnic group, and a cultural group indicates that the Jewish people themselves have a hard time defining what it means to be a Jew in America or at least have a hard time giving a unidimensional definition. 


\section{CHAPTER 5}

\section{DISCUSSION}

The purpose of this study was to investigate the nature of Jewish identity. The findings of this study indicate that those in the college student sample (REP sample) and those who were in the community sample differed on almost all measures in this study. The findings also indicate that Jewish identity is related to measures of well-being in similar patters as other ethnic identities in previous research. This indicates that Jewish identity is an ethnic identity. Jewish religious affiliation was found to be related to Jewish ethnic identity, with Orthodox Jews having the highest scores on ethnic identity, followed by Conservative Jews, followed by Reform participants, followed by those who indicated "other” or "none” as their religious affiliation.

Jewish identification was found to be related to Jewish ethnic identity, but the constructs appear to be separate variables and should thus be treated as such in current and future research. The prediction that Jewish ethnic identity scores are positively correlated with well-being scores was supported by the findings of this study. Jewish ethnic identity was also determined to be related global spirituality and this relationship was moderated by Jewish identification for the community sample, but not the college 
student sample. Jewish identification was also found moderate the relationship between Jewish ethnic identity and extrinsic religiosity for the community sample, but not the college student sample These findings partially support the predictions of this study. Each of these major findings will be discussed in some depth and then implications and areas for further research will be explored in greater detail.

\section{$\underline{\text { Sample Differences }}$}

Since participants of this study came from two different samples they were compared across the different measures in this study to determine if they are similar or different. The two samples, the REP sample, or the college student sample, and the community sample were found to be significantly different in age and on measures of Jewish activity, religious practice, ethnic identity, collective self-esteem, global spirituality, intrinsic religiosity and extrinsic religiosity. Those in the college student sample tended to be younger, score lower on all the measures except extrinsic religiosity. Because such vast differences in the samples exist, they were analyzed separately. However, it should be noted that even though the two samples were different, they were similar in the way that the variables in the study were related to one another.

There may be several reasons why these samples are so different. The age difference may be an important issue. Those in college student sample had a mean age of $18.98(\mathrm{SD}=1.68)$ and those in the community sample had a mean age of 36.54 ( $\mathrm{SD}=15.84)$. On this aspect, the college student sample was very homogeneous, with not very much variance. Also, since the participants in this sample are younger, they may still be developing their ethnic identity, sense of collective self-esteem and spirituality 
and intrinsic religiosity. College is usually the time when students explore their own identities, their religious beliefs, and spirituality, thus, this exploration may account for lower scores on these variables.

Another reason that there may be a difference in these two samples is that the college student sample consisted of only 41 participants, while the community sample consisted of 259 participants. With such a small sample size, it may be hard to make any kind of conclusions about the Jewish college students.

This study points out the importance of using participants from the community and not just college students. The two samples used in this study were different on various measures and the relationships between the variables investigated were different for these samples. These samples could be qualitatively different on aspects such as life experience, maturity level, identity development, marital status, income level, etc. Thus, in order to be able to make generalizations to the general populations, participants should be recruited from various settings, not just a college campus.

Differences between males and females were also investigated. The main differences found were that women had higher scores on the measure of global spirituality and men scored higher on the measure of extrinsic religiosity in the community sample. The difference in spirituality was not found in the initial scale development study for this measure (Purnell, 2004). A possible explanation for this could be that the sample in the current study is different than the sample in the 
development study. In the original study, most of the participants identified themselves as Christian. Also, the version of the GSAI used in the current study is a revised version, and this may also account for the differences found for gender.

$\underline{\text { Jewish Ethnic Identity }}$

In the literature review of this document it was suggested that Jewish identity is an ethnic identity in nature and thus findings from other ethnic identity research should apply to the Jewish people as well. Jewish ethnic identity in this study was measured by the Multigroup Ethnic Identity Measure (Phinney, 1992) and the Collective Self-Esteem Scale (Luhtanen \& Crocker, 1992). Previous research suggests that stronger ethnic identity is related to higher self-esteem (Phinney, 1992) and satisfaction with and adjustment to life (Sasson, 2001). Collective self-esteem has been found to be related to better adjustment to college life (Bettencourt, et al., 1999), satisfaction with life (Mokgatlhe, 1998) and job satisfaction (Mael \& Tetrick, 1992). Researchers have argued that ethnic identity and collective self-esteem may serve a self-protective function for members of stigmatized groups (Crocker \& Major, 1989; Roberts, et al., 1999). In the current study, Jewish ethnic identity was positively correlated with self-esteem and satisfaction with life, and negatively correlated with depression. Jewish ethnic identity was positively correlated with a general well-being score for both the college student sample and the community sample. These results indicate that ethnic identity and collective self-esteem behave similarly for the Jewish people as they do for other ethnic groups investigated in previous studies. These results support Hypothesis 1 of this study. 
Also, the positive correlation of Jewish ethnic identity with well-being may lend some support to the general hypothesis of the self-protective function of ethnic identity suggested by previous researchers.

The literature review of this study discussed the fact that it is very difficult to determine if the Jewish people are a cultural group, an ethnic group, a religious group, or a nationality. The participants of this study were asked to indicate what they thought it meant to be part of the Jewish group in the United States. The results presented show that the choices of religious group, ethnic group, and a cultural group were endorsed by most of the participants in this study. This may indicate that the Jewish people themselves have a hard time agreeing on exactly what kind of a group they are. $\underline{\text { Jewish Identification }}$

Jewish identification was also investigated in this study. A composite measure of Jewish identification was found to be positively correlated with Jewish ethnic identity. For the community sample, Jewish identification was also found to have a weak, but significant, positive correlation with a composite well-being score. This relationship was not found for the REP sample. The composite measure of Jewish identification was made up of two measures: Jewish activities and membership and Jewish religious practices. Involvement in Jewish activities (i.e. reading Jewish literature, visiting places of Jewish interest) and Jewish membership (i.e. belonging to a synagogue) was found to be positively correlated with Jewish ethnic identity for both of the samples in this study. For the community sample, Jewish activities and membership was found to be positively correlated with satisfaction with life, and negatively correlated with depression. For the 
REP sample, Jewish activities and membership was found to be positively correlated with self-esteem and negatively correlated with depression. For both of the samples, however, this aspect of identification, was not found to be correlated with composite measure of well-being.

Another aspect of Jewish identification that was investigated in this study was Jewish religious practices (i.e. lighting candles on Friday nights, celebrating Jewish high holidays, etc.). This aspect of identity was found to be correlated with depression (negative) and self-esteem (positive) for the REP sample. For the community sample, no significant correlation was found between Jewish religious practices and self-esteem, depression, and satisfaction with life. A weak correlation was found for this aspect of identification and a composite measure of well-being for the community sample, but not for the REP sample.

These findings indicate the pattern of relationships with measures of well-being for Jewish ethnic identity and identification are different and that although Jewish identification is related to Jewish ethnic identity, these are separate constructs. Thus, it is important to investigate these as separate variables in current and future research. Religiosity and Spirituality

Previous studies found that religiosity was related to Jewish identification and Jewish ethnic identity (Weisskirch, 2004). The current study found similar results for the community sample. For the participants in this sample, Jewish ethnic identity composite score was positively correlates with scores on intrinsic religiosity and extrinsic religiosity. Identification composite scores were positively correlated with intrinsic 
religiosity, but not with extrinsic religiosity. For the REP sample, the only relationship that was found to be significant was a positive correlation between identification composite score and intrinsic religiosity.

Weisskirch (2004) also found that attendance of synagogue services on Fridays and Saturdays and during Jewish High Holidays, and self reports of Jewish religious practices and rituals were related to stronger ethnic identity. This finding is also supported by the current study. Scores on the Jewish religious practices scale were positively correlated with Jewish ethnic identity composite scores for both samples.

Previous research also indicates that differences exist between Orthodox, Conservative, and Reform Jews on measures of collective self-esteem, spirituality, and well-being (Goodman, 2002). The findings of the current study indicate that individuals of different Jewish religious affiliations do score differently on measures of Jewish ethnic identity, intrinsic religiosity, and Jewish identification. On each of these measures, Orthodox Jews score the highest, followed by Conservative Jews, followed by Reform Jews, followed by those who indicated some other Jewish religious affiliation or no affiliation at all. These findings make sense, because for Orthodox Jews, the religious practices and rituals tend to be a very large part of daily life. These individuals are more likely to live in Jewish communities, close to synagogues. Therefore, since religion is a much bigger part of daily activities for these individuals, their sense of Jewish ethnic identity may be very salient. 


\section{$\underline{\text { Moderation Effects }}$}

Hypothesis 2 of this study predicted that there was a relationship between Jewish ethnic identity and religiosity and spirituality, and that this relationship was moderated by Jewish identification. The results of this study indicate that identification moderates the relationship between Jewish ethnic identity and global spirituality for the community sample, but not the college student sample. This moderation means that there is a positive relationship between Jewish ethnic identity scores and global spirituality, and that this relationship is stronger for those with high identification scores. This relationship makes sense in that those who are involved in more Jewish activities and belong to Jewish organizations, may be encouraged by the organizations and other Jewish people to develop spiritually. Also, since Judaism has a rich mystical and spiritual tradition, those who are involved in more religious practices (and thus have higher identification scores) may be more exposed to spirituality within Judaism.

The results also indicated that identification moderates the relationship between Jewish ethnic identity and extrinsic religiosity, but not intrinsic religiosity for the community sample. For the REP sample, there was no relationship found for ethnic identity and intrinsic or extrinsic religiosity. This moderation effect indicates that there is a positive relationship between Jewish ethnic identity and extrinsic religiosity, and that this relationship is stronger for those with higher identification scores. At first glance, this finding seems counterintuitive. It seems that those who have a stronger Jewish ethnic identity and who are more involved in Jewish activities and religious practices would have higher intrinsic religiosity scores because for these people religiosity would 
be a very meaningful and intrinsically rewarding. However, after further thought, this finding could make sense if those individuals who have higher identification scores join the religious organizations and participate in Jewish ethnic activities because they would like to make more Jewish contacts, or because they feel like they should based on their ethnic identity. This is an interesting finding and more research should be conducted to investigate it further.

\section{Exploratory Hypotheses}

Hypothesis 3 of this study predicted that those participants who had low scores on ethnic identity and high intrinsic religiosity scores, would have low well-being scores. This was suggested because those who find intrinsic value in religiosity, because of the nature of Jewish faith, should also find Jewish identity very important. This hypothesis predicts that because of the possible internal conflict that this can pose, these individuals would have lower well-being scores. The results of this study indicate that the individuals with low ethnic identity scores and high intrinsic religiosity scores had wellbeing scores that were significantly lower than those wit high ethnic identity and low intrinsic religiosity for both the community sample and the college student sample. It is hard to draw conclusions from this finding because the sample size of participants who had low ethnic identity scores and high intrinsic religiosity was small for both the community sample and the college student sample. However, this finding does suggest that further research in this area needs to be done to investigate this group and any possible internal conflict that may be influencing their well-being. 
Hypothesis 4 of this study focused on the relationship between Jewish ethnic identity and Jewish identification. Because not all Jews who value their Jewishness choose to join Jewish organizations and participate in traditionally Jewish activities, it was predicted that for those with high identification scores, there will be a strong positive correlation with identity scores. This prediction was supported by the findings of this study for the community. The second prediction of this hypothesis was that for those with low identification scores, the relationship between identification and identity would be unclear or not as strong. This prediction was not supported by the results of this study. In fact, the opposite was found. For both samples of participants, for those who had low identification scores, there was a strong, positive correlation between identification and ethnic identity. This relationship was stronger for low identifiers than high identifiers. Thus, the finding of this study is the opposite of the prediction of Hypothesis 3b. This finding may support the conclusions of previous studies that identification is very important to formation of strong Jewish ethnic identity. The relationship between Jewish ethnic identity and identification seems to be especially strong for those members who have low identification scores. For those individuals, small changes in identification result in larger changes in Jewish ethnic identity that for the high identifiers. This is an important finding because much efforts in the Jewish community has been directed at encouraging the younger generations to join Jewish organizations and join the Jewish community. The thought behind this effort has been that this will produce stronger Jews 
with stronger Jewish identity. The findings of this study support that effort. More research needs to be done to investigate what kinds of Jewish identification have the most influence on Jewish ethnic identity.

\section{Implications and Directions for Future Research}

This study found support for the claim that Jewish identity is an ethnic identity. The implication of this finding is that the Jewish people need to be included in the crosscultural discussions and research. It is important for counselors working with this population to know that they are not just working with clients who hold certain religious beliefs, but that these clients come from a different ethnic and cultural group. The membership in this group and strong Jewish ethnic identity may lead to higher wellbeing. However, in the current society, this membership may also cause individuals conflict and be a source of stress. The Jewish people are a small minority in the United States. They are also an invisible minority in that they are usually unrecognizable on sight. This may have allowed this group more freedom to succeed, but also this may bring some internal conflict and in extreme cases, internalized anti-Semitism. Further research should investigate how being part of an invisible minority may influence negative feelings toward being Jewish for some members of this group.

This study also found that the relationship between ethnic identity and identification is stronger for those who are least identified. Further research in this area needs to be done. Although finding these participants is difficult, more research needs to be done with the least identified members of the Jewish people. 


\section{$\underline{\text { Limitations }}$}

It is important to point out that there are some methodological problems in this study. The research was conducted using an online survey. Thus, all the participants in this study had to be computer literate, and for the community sample, belong to some organization or listserve that could send them the questionnaire. Also, there was a 66\% response rate for the community sample. There may be something different between these individuals who decided to finish the survey and those who did not. In its entirely, though, this study does hold some interesting findings and raise some interesting questions and directions for future research. It is important to keep this line of research going because very little current research on the Jewish people exists, and this research is needed for counselors and other professionals to be able to provide services to this population. This research is also needed to help the Jewish people understand themselves better and strive for stronger and more positive ethnic identity. 


\section{LIST OF REFERENCES}

Alexrod, M., Fowler, J.F., \& Gurin, A. (1967). A community survey for long range planning: A study of the Jewish population of greater Boston. Boston: Combined Jewish Philanthropies.

Allport, C. W. \& Ross, J. M. (1967). Personal religious orientation and prejudice. Journal of Personality and Social Psychology, 5, p. 432-443.

Amyot, R. P., \& Sigelman (1996). Jews without Judaism? Assimilation and Jewish identity in the United States. Social Science Quarterly, 77, p. 177-189.

Barth, F. (1969). Ethnic groups and boundaries: The social organization of cultural difference. Bergen, Norway: Universitetsforlaget.

Bettencourt, B. A., Charlton, J. E., Kernahan, C., \& Fuller, B. (1999). Development of collective self-esteem among students: Predicting adjustment to college. Basic and Applied Social Psychology, 21, p. 213-222.

Bock, G. E. (1976). The Jewish schooling of American Jews: A study of non-cognitive educational effects. Unpublished doctoral dissertation, Harvard University.

Bowen, D. J., Singal, R., Eng, E., Crystal, S., \& Burke, W. (2003). Jewish identity and intentions to obtain breast cancer screening. Cultural Diversity and Ethnic Minority Psychology, 9, p. 79-87.

Bradburn, N. M., \& Caplovitz, D. (1965). Reports of happiness. Chicago: Aldine.

Casas, J.M. (1984). Policy, training, and research in counseling psychology: The racial/ethnic minority perspectinve. In S.D. Brown and R.W. Lent (Eds.), Handbook of counseling psychology (p. 785-831). New York: John Wiley \& Sons.

Cohen, E. (1977). On the nature of Jewish identity: A methodological approach. An unpublished dissertation. Indiana University. 
Cohen, S. M. (1995). The impact of varieties of Jewish education upon Jewish identity: An inter-generational perspective. Contemporary Jewry, 16, p. 68-96.

Constantinou, S., \& Harvey, M. (1985). Dimensional structure and intergenerational differences in ethnicity: The Greek Americans. Sociology and Social Research, 69, p. 234-254.

Crocker, J., \& Luhtanen, R. (1990). Collective self-esteem and ingroup bias. Journal of Personality and Social Psychology, 58, 60-67.

Crocker, J., \& Major, B. (1989). Social stigma and self-esteem: The self-protective properties of stigma. Psychological Review, 96, p. 608-630.

Cross, W. Jr. (1995). The psychology of nigrescence: Revising the Cross model. In Handbook of Multicultural Counseling. Ponterotto, J., Casas, J. M., Suzuki, L., \& Alexander, C. (Eds.). pp. 93-122. Thousand Oaks, CA: Sage.

Cross W. E. Jr., Smith, L., \& Payne, Y. (2002). Black identity: A repertoire of daily enactments. In P. B. Pedersen, J. G. Draguns, W.J. Lonner, J.E. Trimble (Eds.), Counseling across culture (pp. 93-107). Thousand Oaks: Sage Publications.

Dashefsky, A., \& Shapiro, H. (1974). Ethnic identification among American Jews: Socialization and social structure. Lexington, MA: Lexington Books.

Diener, E., Emmons, R. A., Larsen, R. J., \& Griffen, S. (1985). The satisfaction with life scale. Journal of personality assessment, 49, p. 71-75.

Diener, E., \& Diener, C. (1996). Most people are happy. Psychological Science, 7, p. 181-185.

Diener, E., \& Diener, M. (1995). Cross-cultural correlates of life satisfaction and selfesteem. Journal of Personality and Social Psychology, 68, p. 653-663.

Diener, E., Lucas, E., \& Oishi, S. (2002). Subjective well-being. In C. R. Snyder, \& S. J. Lopez (Eds.) Handbook of Positive Psychology, p. 63-73. Oxford: University Press

Diener, E., Suh, E. M., Lucas, R. E., \& Smith, H. L. (1999). Subjective well-being: Three decades of progress. Psychological Bulletin, 125, p. 276-302.

Donin, H. (1991). To Be a Jew: A Guide to Jewish Observance in Contemporary Life. New York: Basic Books. 
Dubow, E. F., Pargament, K. J., Boxer, P., \& Tarakeshwar, N. (2000). Initial investigation of Jewish early adolescents' ethnic identity, stress, and coping. Journal of Early Adlolescence, 20, p. 418-441.

Erikson, E. (1968). Identity: Youth and crisis. New York: Norton.

Friedman, M. L., Friedlander, M. L., \& Blustein, D. L. (2005). Toward an understanding of Jewish identity: A phenomenological study. Journal of Counseling Psychology, 52, p. 77-83.

Frommer, M. K., \& Frommer, H. (1995). Growing Up Jewish in America: An Oral History. New York: Harcourt Brace.

Fujita, F. (1991). An investigation of the relation between extraversion, neuroticism, positive affect, and negative affect. Unpublished masters thesis, University of Illinois at Urbana-Champagn.

Garcia, J. (1982). Ethnicity and Chicanos: Measurement of ethnic identification, identity, and consciousness. Hispanic Journal of Behavioral Science, 4, p. 395-314.

Goldstein, S. \& Goldscheider, C. (1968). Jewish Americans: Three generations in a Jewish community. Englewood Cliffs, NJ: Prentice-Hall

Goodman, J. M. (2002). Psychological well-being in the Jewish community: The impact of social identity and spirituality. Doctoral dissertation, Kent State University.

Helminiak, D. A. (2001). Treating spiritual issues in secular psychotherapy. Counseling and Values, 45, p. 163-189.

Helms, J. E. (1993). Introduction: Review of racial identity terminology. In. Helms, J.E. (Ed.) Black and white racial identity, p. 3-8. Westport, CT: Praeger.

Herman, S. N. (1962). American Jewish students in Israel. Journal of Social Studies, 24, p. 3-29.

Herman, S. N. (1970). Israeli and Jews: The continuity of identity. New York: Random House.

Herman, S. N. (1989). Jewish Identity: A social psychological perspective. New Brunswick: Transaction Publishers. 
Himmelfarb, H.S. (1979). Patterns of assimilation-identification among American Jews. Ethnicity, 6, p. 249-267.

Himmelfarb, H. S. (1980). The study of American Jewish identification: How it is defined, measured, obtained, sustained and lost. Journal for the Scientific Study of Religion, 19, p. 48-60.

Himmelfarb, H. S. (1982). Research on American Jewish identity and identification: Progress, pitfalls, and prospects. In Understanding American Jewry. Sklare, M. (Ed.). New Brunswick: Transaction Books.

Himmelfarb, H.S., \& Loar, R. M. (1979). National trends in Jewish ethnicity: A test of the polarization hypothesis. The Ohio State University, Department of Sociology.

Hofman, J. E., \& Zak, I. (1969). Interpersonal contact and attitude change in crosscultural situation. Journal of Social Psychology, 78, p. 165-171.

Kane, R., Riegler, S., Bell, R., Potter, R., \& Koshland, G. (1982). Predicting the course of nursing home patients: A progress report. California: The Rand Corporation.

Kaufman, G., \& Raphael, L. (1987). Shame: A perspective on Jewish identity. Journal of Psychology and Judaism, 11, p. 30-40.

Kivisto, P., \& Nefzger, B. (1993). Symbolic ethnicity and American Jews: The relationship of ethnic identity to behavior and group affiliation. The Social Science Journal, 30, p. 1-12.

Klein, J.W. (1977). Jewish identity and slef-esteem. Unpublished doctoral dissertation. Wright Institute, Berkeley, California.

Klein, J.W. (1980). Jewish identity and self-esteem: Healing wounds through enthnotherapy. Institute on Pluralism and Group Identiy of the American Jewish Committee.

Krogman, W.M. (1945). The concept of race. In R. Linton (Ed.), The science of man in world crisis (p. 38-61). New York: Anchor Press/Doubleday.

Langman, P. F. (1995). Including Jews in multiculturalism. Journal of Multicultural Counseling and Development, 23, p. 222-237.

Langman, P. F. (1999). Jewish Issues in Multiculturalism: A Handbook for Educators and Clinicians. Northvale, NJ: Jason Aronson, Inc. 
Lazerwitz, B. (1973). Religious identification and its ethnic correlates. Social Forces, 52, p. 204-220.

Lazerwitz, B. (1978). An approach to the components and consequences of Jewish identification. Contemporary Jewry, 4, p. 3-8.

Lemish, P. (1981). Hanukah bush: The Jewish experience in America. Theory into Practice, 20, p. 26-34.

Lerner, M. (1992). The Socialism of Fools: Anti-Semitism on the Left. Oakland, CA: Tikkun Books.

Luhtanen, R., \& Crocker, J. (1992). A collective self-esteem scale: Self-evaluation of one’s social identity. Personality and Social Psychology Bulletin, 18, p. 302-318.

Lucas, R. E., Diener, E., Grob, A., Suh, E. M., \& Shao, L. (1998). Cross-cultural evidence for the fundamental features of extraversion: The case against sociability. Manuscript submitted for publication, University of Illinois at Urbana-Champaign.

Mael, F. A., \& Tetrick, L. E. (1992). Identifying organizational identification. Educational and Psychological Measurement, 52, p. 813-824.

Marsella, A. J., \& Kameoka, V. A. (1989). Ethnocultural issues in the assessment of psychopathology. In S. Wetzler (Ed.), Measuring mental illness: Psychometric assessment for clinicians (p. 231-256). Washington, DC: American Psychiatric Press.

Metropolitan New York Coordinating Counsil on Jewish Poverty. (1993). Jewish poverty in New York City in the 1990's. (Preliminary Report: April, 1993). New York: Author.

Miller, D. R. (1963). The study of social relationships: Situation, identity, and social interaction. In Koch, S. (Ed.), Psychology: A study of a science (p.673). New York, NY: McGraw-Hill.

Mokgatlhe, B. P., \& Schoeman, J. B. (1998). Predictors of satisfaction with life: The role of racial identity, collective self-esteem and gender-role attitudes. South African Journal of Psychology, 28, p. 28-35.

Parham, T., \& Helms, J. (1981). The influence of black student's racial identity attitudes on preferences for counselor's race. Journal of Counseling Psychology, 28, p. 250-257. 
Phinney, J. (1989). Stages of ethnic identity development in minority group adolescents. Journal of Early Adolescence, 9, p. 34-49.

Phinney, J. S. (1992). The multigroup ethnic identity measure: A new scale for use with diverse groups. Journal of Adolescent Research, 7, p. 156-176.

Phinney, J., \& Alipuria, L. (1990). Ethnic identity in college students from four ethnic groups. Journal of Adolescence, 13, p. 171-183.

Piedmont, R. L. (1999). Does spirituality represent the sixth factor of personality? Spiritual transcendence and the five-factor model. Journal of Personality, 67, p. 985-1013.

Purnell, J. Q. J. (2004). Development of the global spirituality assessment inventory. Unpublished master’s thesis, The Ohio State University, Columbus, $\mathrm{OH}$.

Radloff, L. S. (1977). Center for epidemiological studies depression scale. Applied psychological measurement, 1, p. 385-401.

Ridley, C. R., Li, L. C., Hill, C. L. (1998). Multicultural assessment: Reexamination, reconceptualization, and practical application. The Counseling Psychologist, 26, p. 827-910.

Roberts, R. E., Phinney, J. S., Masse, L. C., Chen, Y. R., \& Romero, A. (1999). The structure of ethnic identity of young adolescents from diverse ethnocultural groups. Journal of Early Adolescence, 19, p. 301-322.

Robbins, M. B.(2000). The Impact of a Trip to Israel on the Jewish, Ethnic and Ego Identity Development of Jewish-American High School Students. Ph. D. Thesis, California School of Professional Psychology. Berkeley/Alameda.

Rosen, B. (1965). Adolescence and religion: The Jewish teenager in American society. Cambridge, MA: Schenkman, 1965.

Rosenberg, M. (1965). Society and the Adolescent Self-Image. Princeton, NJ: Princeton University Press.

Sarnoff, I. (1951). Identification with the aggressor: Some personality correlates of antiSemitism among Jews. Journal of personality, 20, p. 119-218.

Sasson, S. (2001). The impact of ethnic identity upon the adjustment and satisfaction of Jewish and African American residents in a long-term care facility. Social Work in Health Care, 33, p. 89-104). 
Segalman, R. (1966). Self-hatered among Jews: A test of the Lewinian hypothesis of marginality of the Jewish leadership. An unpublished doctoral dissertation. New York University.

Singh, V. (1977). Some theoretical and methodological problems in the study of ethnic identity: A cross-cultural perspective. New York Academy of Sciences: Annals, 285, p. 32-42.

Sklare, M. \& Greenblum, J. (1967). Jewish identity on the suburban frontier. New York: BasicBooks.

Stanard, R.P., Sandhu, D.S., \& Painter, L.C. (2000). Assessment of spirituality in counseling. Journal of Counseling and Development, 78, p. 204-210.

Sue, D.W., Arredondo, P., \& McDavis, R. (1992). Multicultural counseling competencies and standards: A call to the profession. Journal of Multicultural Counseling and Development, 20, p. 64-88.

Suzuki-Crumly, J., \& Hyers, L. L. (2004). The relationship among ethnic identity, psychological well-being, and intergroup competence: An investigation of two biracial groups. Cultural Diversity and Ethnic Minority Psychology, 10, p. 137150.

Ting-Toomey, S. (1981). Ethnic identity and close friendship in Chinese-American college students. International Journal of Intercultural Relations, 5, p. 383-406.

Tajfel, H. (1978). The social psychology of minorities. New York: Minority Rights Group.

Tajfel, H. (1981). Human groups and social categories. New York: Cambridge University Press.

Tajfel, H., \& Turner, J . C. (1986). The social identity theory of intergroup behavior. In S. Worchel \&W. Austin (Eds.), Psychology of intergroup relations ( $2^{\text {nd }}$ ed., pp. 724). Chicago: Nelson-Hall

United Jewish Communities (2003). The National Jewish Population Survey 2001-2002.

United Jewish Communities (2003). PowerPoint Presentation of Findings.

Verbit, M. (1968). Referents of religion among Jewish college students. Unpublished $\mathrm{Ph}$. D. dissertation, Columbia University. 
Verbit, M. F. (1970). The components and dimensions of religious behavior: Toward a reconceptualization of religiosity. In P. E. Hammond \& B. Johnosn (Eds.) American Mosaic, Social Patterns of Religion in the United States. New York: Random House, p. 24-39.

Weinrach, S. G. (2002). The counseling profession's relationship to Jews and the issues that concern them: More than a case of selective awareness. Journal of Counseling and Development, 80, p. 300-314.

Weisskirch, R. S. (2004). Ethnic identity and religious practice among American Jews. Poster presentation presented at 2004 American Psychological Association Annual Convention, Honolulu, HI.

Worthington, E. L., Wade, N. G., Hight, T. L., Ripley, J. S., McCullough, M. E., Berry, J. W., Schmitt, M. M., Berry, J. T., Bursley, K. H., \& O’Connor, L. (2003). The religious commitment inventory-10: Development, refinement, and validation of a brief scale for research and counseling. Journal of Counseling Psychology, 50, p. 84-96.

The World almanac and the book of facts: 1995. (1994). New York: Funk \& Wagnalls.

Zak, I. (1973). Dimensions of Jewish-American Identity. Psychological Reports, 33, p. 891-900. 
APPENDIX A: TABLES 


\begin{tabular}{|c|c|c|c|c|}
\hline & Minimum & Maximum & Mean & Std. Dev. \\
\hline \multicolumn{5}{|l|}{ NJPS } \\
\hline Jewish Activity & 22 & 64 & 49.19 & 9.16 \\
\hline Religious Practice & 0 & 26 & 16.80 & 5.58 \\
\hline \multicolumn{5}{|l|}{ MEIM } \\
\hline Ethnic Identity & 1.36 & 4.00 & 3.42 & 0.52 \\
\hline Affirmation and Belonging & 1.20 & 4.00 & 3.60 & 0.55 \\
\hline Ethnic Identity Achievement & 1.43 & 4.00 & 3.35 & 0.55 \\
\hline Ethnic Behaviors & 1.00 & 4.00 & 3.22 & 0.80 \\
\hline Other Group Orientation & 1.67 & 4.00 & 3.49 & 0.49 \\
\hline Overall Score & 1.36 & 4.00 & 3.42 & 0.52 \\
\hline \multicolumn{5}{|l|}{ CSER } \\
\hline Membership Self-Esteem & 1.25 & 7.00 & 5.88 & 1.13 \\
\hline Private Collective Self-Esteem & 1.00 & 3.75 & 1.50 & 0.58 \\
\hline Public Collective Self-Esteem & 1.75 & 7.00 & 5.18 & 0.93 \\
\hline Importance to Identity & 1.00 & 7.00 & 5.64 & 1.42 \\
\hline Overall score & 2.81 & 7.00 & 5.80 & 0.80 \\
\hline Depression & 0 & 48 & 11.45 & 9.37 \\
\hline Rosenberg Self-Esteem & 18 & 40 & 32.93 & 5.15 \\
\hline Satisfaction with Life & 1.00 & 7.00 & 5.23 & 1.23 \\
\hline \multicolumn{5}{|l|}{ GSAI } \\
\hline Transcendent Outlook & 26 & 48 & 39.39 & 4.57 \\
\hline Transcendent Truth Experience & 26 & 58 & 43.68 & 5.90 \\
\hline Openness to Connection & 31 & 55 & 45.61 & 4.46 \\
\hline Connection to Self and Others & 29 & 55 & 45.00 & 5.11 \\
\hline Moral Purpose & 23 & 53 & 42.86 & 4.46 \\
\hline Personal Strength & 23 & 50 & 40.09 & 5.19 \\
\hline Overall Score & 190 & 305 & 256.62 & 22.16 \\
\hline \multicolumn{5}{|l|}{ ROS } \\
\hline Intrinsic Religiosity & 1.00 & 4.77 & 3.11 & 0.80 \\
\hline Extrinsic Religiosity & 1.00 & 4.88 & 2.69 & 0.62 \\
\hline
\end{tabular}

$\mathrm{N}=300$

Table 1: Descriptive Statistics for All Variables 


\begin{tabular}{|c|c|c|c|c|c|}
\hline \multirow[b]{2}{*}{ Variable } & \multicolumn{2}{|c|}{$\operatorname{REP}(\mathrm{N}=41)$} & \multicolumn{2}{|c|}{ Community $(\mathrm{N}=258)$} & \multirow[b]{2}{*}{$\mathrm{t}$} \\
\hline & $\mathrm{M}$ & SD & $\mathrm{M}$ & SD & \\
\hline Age & 18.98 & 1.68 & 36.54 & 15.84 & $7.09 * *$ \\
\hline \multicolumn{6}{|l|}{ NJPS } \\
\hline Jewish Activity & 11.76 & 6.70 & 17.59 & 4.95 & $5.35^{* *}$ \\
\hline Religious Practice & 42.66 & 8.28 & 50.22 & 8.88 & $5.11^{* *}$ \\
\hline MEIM & 2.94 & 0.53 & 3.50 & 0.48 & $6.77^{* *}$ \\
\hline CSER & 4.98 & 0.92 & 5.93 & 0.70 & $6.33^{* *}$ \\
\hline Depression & 12.44 & 8.59 & 11.28 & 9.49 & 0.74 \\
\hline Rosenberg Self-Esteem & 33.29 & 5.54 & 32.88 & 5.10 & 0.48 \\
\hline Satisfaction with Life & 5.51 & 1.06 & 5.19 & 1.25 & 1.58 \\
\hline GSAI & 243.79 & 22.19 & 258.65 & 21.51 & $4.09 * *$ \\
\hline \multicolumn{6}{|l|}{ ROS } \\
\hline Intrinsic Religiosity & 2.70 & 0.56 & 3.18 & 0.81 & $4.78 * *$ \\
\hline Extrinsic Religiosity & 3.08 & 0.66 & 2.62 & 0.59 & $4.53^{* *}$ \\
\hline
\end{tabular}

Table 2: Comparison of Means for the Research Experience Program Sample and the Community Sample for All Variables. 


\begin{tabular}{|c|c|c|c|c|c|}
\hline \multirow[b]{2}{*}{ Variable } & \multicolumn{2}{|c|}{ Male $(\mathrm{N}=18)$} & Female $(\mathrm{N}=23)$ & \multirow[b]{2}{*}{ SD } & \multirow[b]{2}{*}{$\mathrm{t}$} \\
\hline & $\mathrm{M}$ & SD & $\mathrm{M}$ & & \\
\hline MEIM & & & & & \\
\hline $\begin{array}{l}\text { Other Group Orientation } \\
\text { GSAI }\end{array}$ & 3.24 & 0.48 & 3.64 & 0.38 & $3.02 *$ \\
\hline $\begin{array}{l}\text { Openness to Connection } \\
\text { ROS. }\end{array}$ & 40.69 & 5.20 & 45.30 & 3.21 & $3.53^{* *}$ \\
\hline Extrinsic Religiosity & 3.41 & 0.60 & 2.82 & 0.60 & $3.12^{* *}$ \\
\hline
\end{tabular}

Table 3: Comparison of means for gender for the Research Experience Program sample 


\begin{tabular}{|c|c|c|c|c|c|}
\hline \multirow[b]{2}{*}{ Variable } & \multicolumn{2}{|c|}{ Male $(\mathrm{N}=85)$} & \multicolumn{2}{|c|}{ Female ( $\mathrm{N}=171)$} & \multirow[b]{2}{*}{$\mathrm{t}$} \\
\hline & $\mathrm{M}$ & SD & $\mathrm{M}$ & $\mathrm{SD}$ & \\
\hline Age & 41.04 & 18.40 & 34.20 & 13.74 & $3.34^{* *}$ \\
\hline \multicolumn{6}{|l|}{ MEIM } \\
\hline Other Group Orientation & 3.37 & 0.58 & 3.55 & 0.44 & $2.44^{* *}$ \\
\hline \multicolumn{6}{|l|}{ GSAI } \\
\hline Transcendent Truth Experience & 42.49 & 7.00 & 45.21 & 4.93 & $3.21^{* *}$ \\
\hline Openness to Connection & 44.39 & 4.63 & 46.73 & 4.65 & $4.20 * *$ \\
\hline Connection to Self and Others & 43.77 & 5.26 & 46.10 & 4.65 & $3.61^{* *}$ \\
\hline Moral Purpose & 42.79 & 4.71 & 43.88 & 3.76 & $2.01^{*}$ \\
\hline Overall Score & 252.45 & 23.76 & 261.96 & 19.58 & $2.41 * *$ \\
\hline
\end{tabular}

Table 4: Comparison of means for the gender for Community Sample 


\begin{tabular}{llllll}
\hline Variable & $\begin{array}{l}\text { Orthodox } \\
\mathrm{M}(\mathrm{SD})\end{array}$ & $\begin{array}{c}\text { Conservative } \\
\mathrm{M}(\mathrm{SD})\end{array}$ & $\begin{array}{c}\text { Reform } \\
\mathrm{M}(\mathrm{SD})\end{array}$ & $\begin{array}{c}\text { Other } \\
\mathrm{M}(\mathrm{SD})\end{array}$ & $\begin{array}{l}\text { None } \\
\mathrm{M}(\mathrm{SD})\end{array}$ \\
\hline $\begin{array}{l}\text { NJPS } \\
\text { Jewish Activity }\end{array}$ & $20.20(3.03)$ & $19.08(4.01)$ & $16.91(4.37)$ & $17.14(4.96)$ & $12.48(6.03)$ \\
$\quad$ Religious Practice & $60.25(2.75)$ & $53.46(5.77)$ & $47.54(7.06)$ & $48.09(10.93)$ & $10.58(10.16)$ \\
MEIM & $3.69(.41)$ & $3.61(.36)$ & $3.48(.45)$ & $3.43(.50)$ & $3.05(.67)$ \\
CSER & $6.11(.54)$ & $6.11(.56)$ & $5.92(.69)$ & $5.78(.80)$ & $5.31(.83)$ \\
ROS & & & & & $2.63(.80)$ \\
Intrinsic Religiosity & $3.97(.56)$ & $3.34(.72)$ & $3.03(.76)$ & $2.95(.89)$ & $-0.61(1.14)$ \\
Jewish Ethnic Identity Factor & $0.33(.68)$ & $0.36(.61)$ & $0.19(.86)$ & $0.04(1.02)$ & $-0.94(1.05)$ \\
Identification Factor & $1.00(.35)$ & $0.48(.65)$ & $-0.09(.75)$ & $-0.03(1.05)$ & - \\
\hline
\end{tabular}

Orthodox N=20

Conservative $\mathrm{N}=104$

Reform N=69

Other $\mathrm{N}=37$

None $\mathrm{N}=27$

Table 5: Means for Variables That Significantly Differ by Religious Affiliation for the Community Sample. 


\begin{tabular}{|c|c|c|c|c|c|c|c|c|c|c|c|c|c|}
\hline Measures & 1 & 2 & 3 & 4 & 5 & 6 & 7 & 8 & 9 & 10 & 11 & 12 & 13 \\
\hline 1. MEIM Ethnic Identity & & $.76^{* *}$ & .24 & $-.52 * *$ & $.47 * *$ & .28 & .22 & $.41 * *$ & $.65^{* *}$ & $.71 * *$ & $.91^{* *}$ & $.49 * *$ & $.75^{* *}$ \\
\hline 2. Collective Self-Esteem & $.65^{* *}$ & & .27 & $-.47 * *$ & $.48 * *$ & .20 & .07 & $.42 * *$ & $.65^{* *}$ & $.67 * *$ & $.94^{* *}$ & $.48^{* *}$ & $.74^{* *}$ \\
\hline 3. Satisfaction with Life & $.18^{* *}$ & $.23^{* *}$ & & $-.46 * *$ & $.63^{* *}$ & -.06 & .11 & $.54 * *$ & .01 & .15 & .29 & $.80^{*}$ & .08 \\
\hline 4. Depression & $-.20 * *$ & $-.18 * *$ & $-.57 * *$ & & $-.71^{* *}$ & -.02 & -.14 & $-.60 * *$ & -.28 & $-.33 *$ & $-.56 * *$ & $-.84 * *$ & $-.34 *$ \\
\hline 5. Self-Esteem & $.17 * *$ & $.21^{* *}$ & $.64^{* *}$ & $-.63 * *$ & & -.07 & -.07 & $.70 * *$ & .25 & $.36^{*}$ & $.55^{* *}$ & $.93 * *$ & $.33^{*}$ \\
\hline 6. Intrinsic Religiosity & $.41 * *$ & $.48^{* *}$ & .06 & -.06 & .05 & & $.43^{* *}$ & .02 & .26 & $.50 * *$ & .20 & -.05 & $.40 * *$ \\
\hline 7. Extrinsic Religiosity & $.13^{*}$ & .12 & -.01 & .05 & -.05 & .01 & & -.07 & .26 & .28 & .09 & .06 & .30 \\
\hline 8. Global Spirituality & .11 & $.21^{* *}$ & $.40^{* *}$ & $-.28 * *$ & $.47 * *$ & $.33^{* *}$ & -.50 & & .14 & .14 & $.52 * *$ & $.72 * *$ & .16 \\
\hline 9. Jewish Act. \& Mem. & $.62 * *$ & $.59 * *$ & $.14^{*}$ & $-.15 *$ & .09 & $.49 * *$ & $.15^{*}$ & .10 & & $.62 * *$ & $.67 * *$ & .22 & $.93 * *$ \\
\hline 10. Jewish Rel. Act. & $.54 * *$ & $.54^{* *}$ & .10 & -.12 & .04 & $.72 * *$ & .07 & $.16^{* *}$ & $.61^{* *}$ & & $.71^{* *}$ & $.34 *$ & $.87 * *$ \\
\hline 11. Jewish Ethnic Identity & $.89 * *$ & $.87 * *$ & $.24 * *$ & $-.21 * *$ & $.25 * *$ & $.44^{* *}$ & $.12^{*}$ & $.25 * *$ & $.63^{* *}$ & $.52 * *$ & & $.55^{* *}$ & $.76^{* *}$ \\
\hline 12. Well-Being & $.22 * *$ & $.24 * *$ & $.24^{* *}$ & $-.85 * *$ & $.88^{* *}$ & .06 & -.04 & $.45^{* *}$ & $.15^{*}$ & .10 & $.27 * *$ & & .30 \\
\hline 13. Identification & $.65^{* *}$ & $.63^{* *}$ & $.13^{*}$ & $-.13 *$ & .07 & $.68 * *$ & .12 & $.15^{*}$ & $.89 *$ & $.91^{* *}$ & $.64^{* *}$ & $.14^{*}$ & \\
\hline
\end{tabular}

Note: Correlations below the diagonal are for the Community sample and those above the diagonal are for the REP sample.

REP Sample $\mathrm{N}=41$

Community Sample $\mathrm{N}=259$

$* \mathrm{p}<.05, * * \mathrm{p}<.01$

Table 6: Correlations Between Scores on MEIM Ethnic Identity, Collective Self-Esteem, Satisfaction with Life, Depression, Self-Esteem, Intrinsic Religiosity, Extrinsic Religiosity, Global Spirituality, Jewish Activities and Membership, Jewish Religious Activities, Jewish Ethnic Identity Factor, Well-Being Factor, and Identification Factor for REP Sample and Community Sample. 


\begin{tabular}{|c|c|c|c|c|c|c|c|c|}
\hline & \multirow[b]{2}{*}{ Predictor Model } & \multicolumn{3}{|c|}{ Results of Regression } & \multicolumn{2}{|c|}{ Change Statistics } & \multirow[b]{2}{*}{$p$} & \multirow{2}{*}{$\begin{array}{l}\text { Moderation } \\
\text { Conclusion }\end{array}$} \\
\hline & & $R^{2}$ & $F$ & $p$ & Change in $R^{2}$ & $F$ Change & & \\
\hline \multicolumn{9}{|c|}{ Regression 1: Dependent variable - GSAI } \\
\hline 1 & Ethnic Identity Factor & .062 & 17.07 & .001 & .062 & 17.07 & .001 & \\
\hline 2 & Identification Factor & .062 & 8.53 & .001 & .000 & .056 & .814 & \\
\hline 3 & Interaction & .109 & 10.381 & .001 & .046 & 13.26 & .001 & Yes \\
\hline \multicolumn{9}{|c|}{ Regression 2: Dependent variable - Intrinsic Religiosity } \\
\hline 1 & Ethnic Identity Factor & .189 & 59.94 & .001 & .189 & 59.94 & .001 & \\
\hline 2 & Identification Factor & .463 & 110.41 & .001 & .274 & 130.65 & .001 & \\
\hline 3 & Interaction & .470 & 75.33 & .001 & .007 & 3.24 & .073 & No \\
\hline \multicolumn{9}{|c|}{ Regression 3: Dependent variable - Extrinsic Religiosity } \\
\hline 1 & Ethnic Identity Factor & .015 & 2.97 & .047 & .015 & 3.97 & .047 & \\
\hline
\end{tabular}

Table 7: Regression Analyses for Prediction of Global Spirituality, Intrinsic Religiosity, and Extrinsic Religiosity by Ethnic Identity Factor and Identification Factor, for the Community Sample ${ }^{1}$.

\footnotetext{
${ }^{1}$ Format for this table came from Tokar, Withrow, Hall, and Moradi, 2003
} 


\begin{tabular}{|c|c|c|c|c|c|c|c|c|}
\hline \multirow{2}{*}{\multicolumn{2}{|c|}{ Predictor Model }} & \multicolumn{3}{|c|}{ Results of Regression } & \multicolumn{3}{|c|}{ Change Statistics } & \multirow{2}{*}{$\begin{array}{r}\text { Moderation } \\
\text { Conclusion }\end{array}$} \\
\hline & & $R^{2}$ & $F$ & $p$ & Change in $R^{2}$ & $F$ Change & $p$ & \\
\hline \multicolumn{9}{|c|}{ Regression 1 : Dependent variable - GSAI } \\
\hline 1 & Ethnic Identity Factor & .272 & 14.58 & .001 & .272 & 14.58 & .001 & \\
\hline 2 & Identification Factor & .406 & 12.96 & .001 & .133 & 8.53 & .006 & \\
\hline 3 & Interaction & .412 & 8.64 & .001 & 006 & .396 & .533 & No \\
\hline
\end{tabular}

Table 8: Regression Analyses for Prediction of Global Spirituality by Ethnic Identity Factor and Identification Factor for the REP Sample ${ }^{1}$.

○ั

\footnotetext{
${ }^{1}$ Format for this table came from Tokar, Withrow, Hall, and Moradi, 2003
} 
APPENDIX B: RECRUITMENT EMAIL FOR RESEARCH EXPERIENCE PROGRAM 
Dear Student,

My name is Regina Kakhnovets and I am a graduate student in the Department of Psychology conducting a research study. My advisor is Dr. Don M. Dell. Based on your responses to the prescreening measures you completed in your Psychology 100 class, I would like to invite you to participate in my study. You will receive 1 hour of REP credit for your participation. Please go on the REP website and look at my study, number CDD2. If you are interested in participating, please sign up for a section that best fits in your schedule.

Please let me know if you have any questions. Also, If you are interested in participating, but can't make the currently scheduled times, please let me know and I will try to work something out.

\section{Sincerely,}

Regina Kakhnovets, M.A.

Doctoral Candidate

Counseling Psychology Program

Department of Psychology 
APPENDIX C: RECRUITMENT EMAIL FOR COMMUNITY SAMPLE 
Dear potential participant,

My name is Regina Kakhnovets, and I am currently a graduate student in the department of Psychology at the Ohio State University. My advisor at OSU is Dr. Don M. Dell. I am conducting a study investigating the relationship between the way that Jewish people think about themselves as Jews and their well-being. I would really appreciate it if you could help me with my research by participating in this study. Your participation would entail filling out various questionnaires online. The time you might spend on this study would be between 30-40 minutes.

If you are Jewish, have a Jewish parent, or were brought up in a Jewish home, I invite you to participate in this study. Your participation will allow us to have more information about the Jewish people and their experience in the United States.

I understand that you probably lead a busy life, so in order to thank you for your time, I am offering 3 prizes of $\$ 50$ to be awarded to the participants. If you decide to participate in this study, you will be entered into a drawing for one of these prizes. The prizes will be awarded when the data collection for this study is finished.

Please understand that all the information you provide in this study will be kept confidential, and no identifying information will be requested from you. The only place where I will ask for your name and contact information will be on your entry into the prize drawing. This information will not be attached from your responses so that they will remain confidential.

In order to participate in my study, please follow the link below. Thank you so much for your time and effort. Please let me know if you have any questions or concerns.

Sincerely,

Regina Kakhnovets, M. A.

Doctoral Candidate, Counseling Psychology Program

Department of Psychology

The Ohio State University
Don M. Dell, Ph. D.

Advisor, Associate Professor Department of Psychology The Ohio State University 
APPENDIX D: STUDY INFORMATION AND CONSENT 


\section{Study Information Page}

[This page provides the participants with answers to common questions they might have about the study, as well as contact information if they have further questions.]

Thank you for your interest in this study. Before beginning, I would like to provide you with some information regarding this study. Please read this carefully. You may want to print out this page so that you can have it after the study is over.

What is the purpose of this study?

The following study focuses on exploring the ways that Jews think about their Jewishness and what it means to them. The purpose of the study is to explore whether the way that Jews think about themselves as Jews is related of other psychological constructs.

What will this study involve?

This study contains several questionnaires that ask a variety of questions regarding one's thoughts, feelings, and behaviors. The study contains approximately 150 one-sentence items to respond to, which altogether should take around 30 to 40 minutes of your time.

Who can participate in this study?

This study is designed only for anyone who is Jewish, has Jewish parents, or was raised in a Jewish home. While there are Jews of many nationalities, this study is focusing on the American Jews. If you do not fit into these characteristics, please do not complete this study.

What are the possible benefits of taking part in this study?

The main benefits of participating in this study lie in the contribution you would make towards further understanding the Jewish experience in the United States. There are likely no direct benefits you would receive.

What are possible disadvantages of taking part in this study?

Given that this study will take about 20 to 40 minutes of your time, you may find this inconvenient. Please take this into account before beginning, and choose a convenient time for yourself to complete it if you wish to do so. Also this study may ask some questions that you find personal, or may make you feel uncomfortable. If this happens, you can simply leave any question blank if you do not wish to answer it. Furthermore, you can end the study at any time simply by closing your web browser.

Will my taking part in this study be kept confidential?

Yes. This study will not request any identifying information from you, such as your name or address. Therefore, your responses are anonymous.

What if I am interested in the results of this study?

You may contact the researchers for this study, listed at the bottom of this page, for more information. 
Who has reviewed this study?

The procedures for this study have been reviewed by the Behavioral and Social Sciences Institutional Review Board at The Ohio State University.

Thank you. If you have any other questions, you may contact:

\section{Dr. Don Dell}

Dell.1@osu.edu

614-688-8287

\section{Regina Kakhnovets}

105 Townshend Hall

1885 Neil Ave

Columbus, OH 43235

614-459-0229

\section{Office of Responsible Research Practices (ORRP)}

Phone: (614)688-8457

Address:

The Ohio State University

Third Floor Research Foundation Building

1960 Kenny Road

Columbus, Ohio

43210-1063

To continue with this study, you will be presented with a brief informed consent form, which describes that you understand several points discussed in this information. To go to the informed consent form and continue with this study, please click here: 


\section{Informed Consent}

By clicking to continue, I indicate that I understand the procedures involved in this study.

I am aware that I have the right to ask questions and receive answers related to this study by contacting the investigators: Dr. Don Dell, dell.1@osu.edu, (614)688-8287; Regina Kakhnovets, M.A., kakhnovets.1@osu.edu, (614) 459-0229. Furthermore, if I have questions about my rights as a research participant, I can call the Office of Research Risks Protection at (614) 688-4792.

I am aware that I have the right to refuse to participate and may withdraw at any time without any penalty, simply by closing my web browser. Furthermore, I know I do not have to answer any question that I do not wish to, and can merely skip such questions. I understand that my participation is voluntary.

To indicate your consent to participate in this study please select Yes below. Making that selection will act as your signature on this form.

Yes, I give my consent to participate in this study. [When participants select this option, they are directed to the beginning of the study]

No, I do not give my consent to participate in this study. [When participants select this option, they will be directed to the end of the study, thanking them for their time. They will not be allowed to answer questions of the study by selecting "No" here.] 
APPENDIX E: DEBRIEFING 
Debriefing Information

Dear Study Participants,

Thank you so much for participating in this study. This research is designed to investigate whether the Jewish ethnic identity of American Jews influences their wellbeing. The hypotheses of the researchers are that those with stronger Jewish ethnic identity, will feel better about themselves, will be less depressed, and will be more satisfied with their lives.

If in the course of this study you have developed concerns or uncertainties about your feelings or about yourself, or if you feel any type of distress related to your responses, you may wish to seek counseling. If you wish to do this, you might be able to find counseling in Townshend Hall at the Psychological Services Center (292-2059). In addition, The Ohio State University Counseling and Consultation Services offers counseling and is open eight hours a day for appointments, and if needed, on an emergency basis. If you need these services please call 292-5766. If you have any other questions about this study or would like additional counseling referrals, please contact Dr. Don Dell at 688-8287 or dell.1@osu.edu.

If you have any concerns about the way that this study was conducted, please contact the Office of Responsible Research Practices at 688-8457.

Again, thank you for assisting us with this research. We hope that it will eventually be used to help others like you. 
APPENDIX F: INSTRUMENTS 


\section{Multigroup Ethnic Identity Measure - Jewish Version}

In this country, people come from a lot of different cultures and there are many different words to describe the difference backgrounds or ethnic groups that people come from. Every person is born into an ethnic group, or sometimes two groups, but people differ on how important their ethnicity is to them, how they feel about it, and how much their behavior is affected by it. These questions are about your Jewish ethnicity and how you feel about it or react to it.

Please use the numbers given below to indicate how much you agree or disagree with each statement about your Jewish ethnicity:

\section{$\begin{array}{llll}4 & 3 & 2 & 1\end{array}$ \\ Strongly Somewhat Somewhat Strongly agree agree disagree disagree}

1. I have spent time trying to find out more about my own ethnic group, such as its history, traditions, and customs.

2. I am active in organizations or social groups that include mostly members of my own ethnic group.

3. I have a clear sense of my ethnic background and what it means for me.

4. I like meeting and getting to know people from ethnic groups other than my own.

5. I think a lot about how my life will be affected by my ethnic group membership.

6. I am happy that I am a member of the group I belong to.

7. I sometimes feel it would be better if different ethnic groups didn't try to mix together.

8. I am not very clear about the role of my ethnicity in my life.

9. I often spend time with people from ethnic groups other than my own.

10. I really have not spent much time trying to learn more about the culture and history of my ethnic group.

11. I have a strong sense of belonging to my own ethnic group. 
12. I understand pretty well what my ethnic group membership means to me, in terms of how to relate to my own group and other groups.

13. In order to learn more about my ethnic background, I have often talked to other people about my ethnic group.

14. I have a lot of pride in my ethnic group and its accomplishments.

15. I don't try to become friends with people from other ethnic groups.

16. I participate in cultural practices of my own group, such as special food, music, or customs.

17. I am involved in activities with people from other ethnic groups.

18. I feel a strong attachment towards my own ethnic group.

19. I enjoy being around people from ethnic groups other than my own.

20. I feel good about my cultural or ethnic background. 


\section{National Jewish Population Survey Identification Scale}

Below you will find some questions about your experiences and beliefs as a Jew in the United States. Please answer all questions as honestly as possible. There are no wrong answers, and the only right ones are whatever you honestly feel, believe, or remember. Please indicate your answ ${ }^{-\cdots-}$ using the answering choices provided for each section.

1. In the past year, I have read a Jewish newspaper, magazine, or other publication....

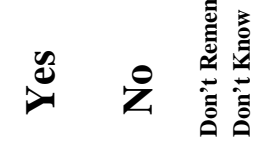

2. In the past year, I have listened to a tape, CD, or record because it contained

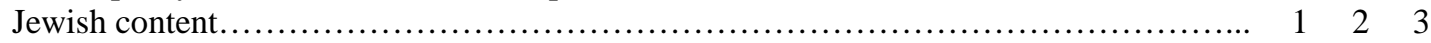

3. In the past year, I have seen a movie, or rented a video because it had Jewish content..... $1 \begin{array}{lllll}1 & 2 & 3\end{array}$

4. In the past year, I have read a book, other than the Bible, because it had Jewish content... 1 r 23

5. In the past year, I have used the internet for Jewish related information.................... $122 \quad 3$

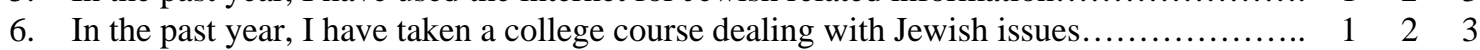

7. In the past year, I have attended an Jewish adult education class (such as a synagogue study group, a book group, etc.)..................................... $122 \quad 3$

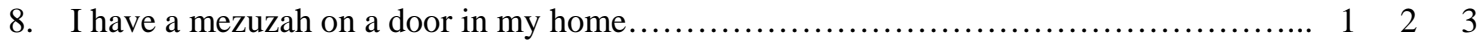

9. In the past year, I have personally experienced anti-Semitism........................ 1 2 3

10. In the past year, I have done volunteer work or made a donation for

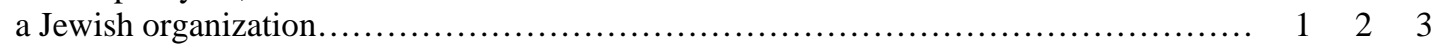

11. In the course of my life, I have visited Israel......................................... $1 \quad 2 \quad 3$

12. I had a Bar/Bat Mitzvah when I reached the appropriate age.......................... $1 \quad 2 \quad 3$

13. I have attended a Jewish sleep-away camp before I was 25 years old................... $1 \quad 2 \quad 3$

14. I am a member of a Jewish Community Center.................................... $1 \quad 2 \quad 3$

15. I am a member of a synagogue.............................................. 1 2 3

16. When you were growing up, did you receive any Jewish education, such as Hebrew school, Sunday school, Jewish day school, or private tutoring?....

Please answer questions 17-28 using the scale provided.

17. How often do you light Sabbath candles on Friday night?

$\begin{array}{lllllll}1 & 1 & 2 & 3 & 4\end{array}$

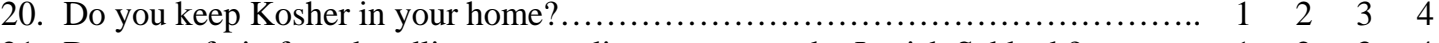

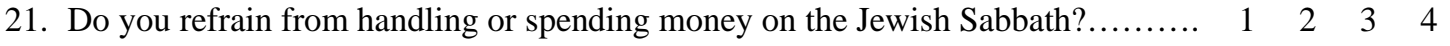

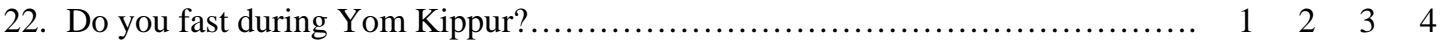

23. Do you ever put up a Christmas tree in your home?.......................... $1 \quad 2 \quad 3 \quad 4$

24. How often do you pray using your own words, when not attending religious services?

25. When I travel, I look for places of Jewish interest.

26. Thinking about your childhood, how often did anyone in your family light Sabbath candles on Friday nights?...

27. Thinking about your childhood, how often did you attend synagogue

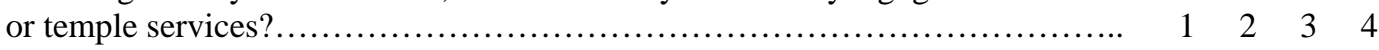

28. Did your family have a Christmas tree when you were a child?................ $1 \quad 2 \quad 3 \quad 4$ 
Please answer questions 29-50 using the scale provided.

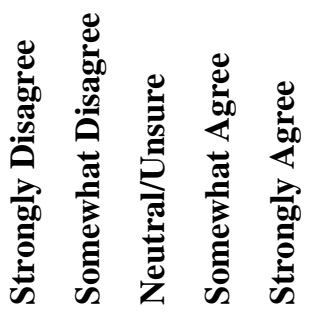

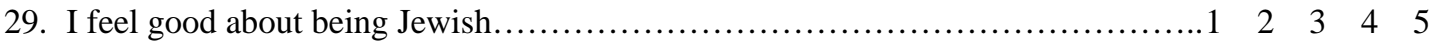

30. I have a clear sense of what being Jewish means to me......................... $1 \quad 2 \quad 3 \quad 4 \quad 5$

31. Jewish in the United States and Jews elsewhere around the world share a

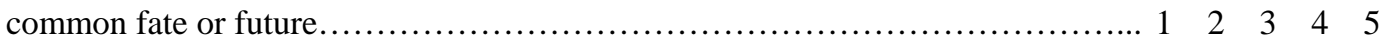

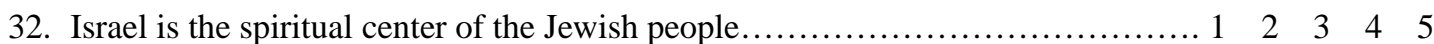

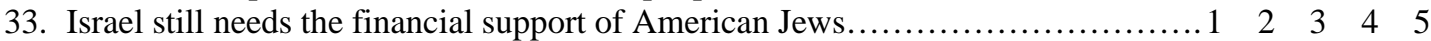

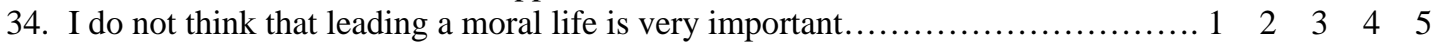

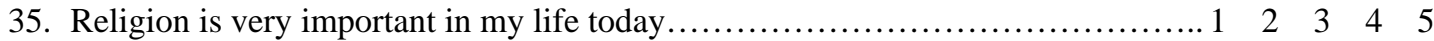

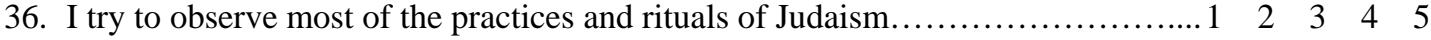

37. I believe that it is important to work towards eliminating anti-Semitism

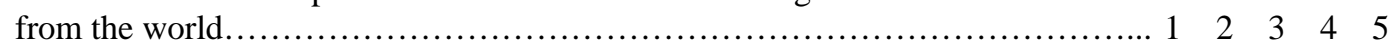

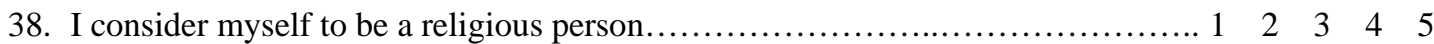

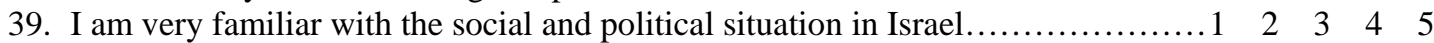

40. I have a special responsibility to take care of Jews in need around the world........1 $12 \begin{array}{lllll}2 & 3 & 4 & 5\end{array}$

41. Overall, the fact that I am a Jew, has very little to do with how I see myself........ $1 \begin{array}{llllll}1 & 2 & 3 & 4 & 5\end{array}$

42. I believe in God........................................................... $122 \quad 3 \quad 4 \quad 5$

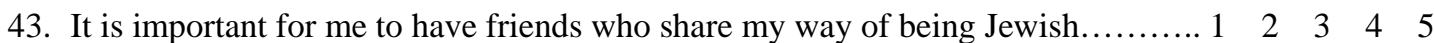

44. When faced with important life decisions, I look to Judaism for guidance.......... $1 \begin{array}{llllll}1 & 2 & 3 & 4 & 5\end{array}$

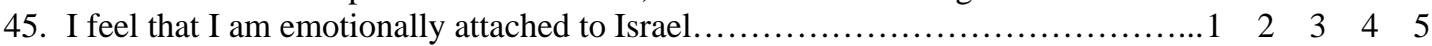

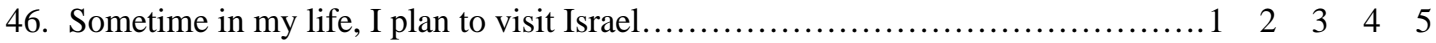

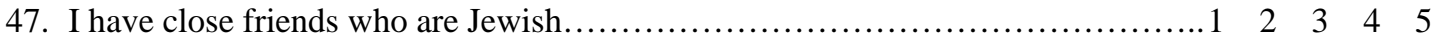

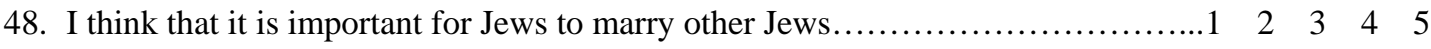

49. I believe that anti-Semitism does not exist in the United States today............... $12 \begin{array}{lllll}2 & 3 & 4 & 5\end{array}$

50. I believe that being Jewish involves:

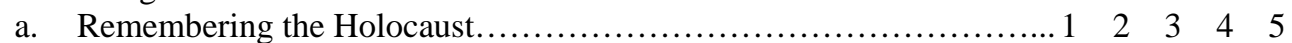

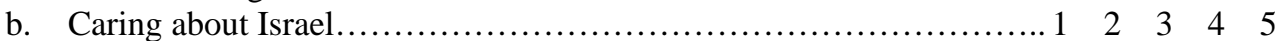

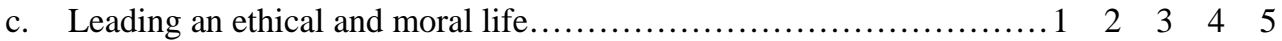

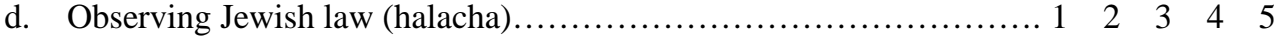

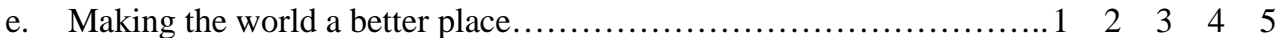

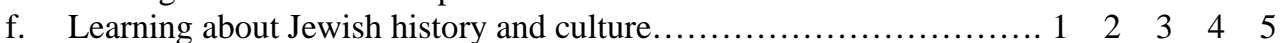

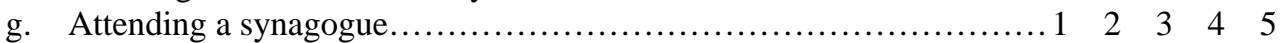

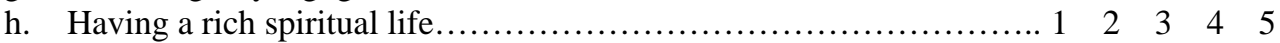

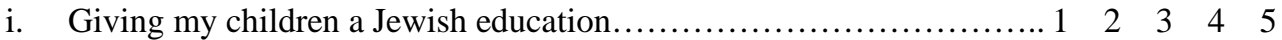

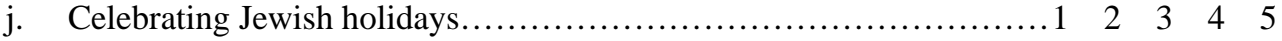

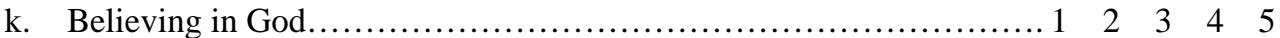

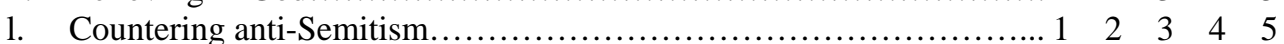

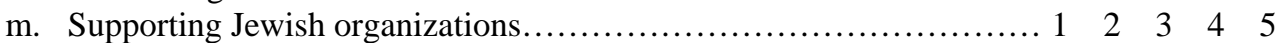

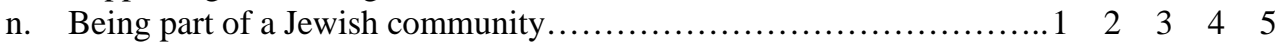

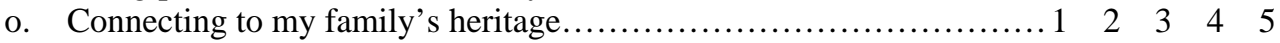

51. Thinking about Jewish religious denominations, what do you consider yourself to be?

52. Being a Jew in America means being a member of the following (please mark all that apply)

A religious group An ethnic group
A cultural group

A nationality
Other 


\section{Collective Self-Esteem}

INSTRUCTIONS: We are all members of different social groups or social categories. We would like you to consider your J ewish ethnic group in responding to the following statements. There are no right or wrong answers to any of these statements; we are interested in your honest reactions and opinions. Please read each statement carefully, and respond by using the following scale from 1 to 7 :

\section{$\begin{array}{lllllll}1 & 2 & 3 & 4 & 5 & 6 & 7\end{array}$ Strongly
disagree Disagree $\begin{gathered}\text { Disagree } \\ \text { somewhat }\end{gathered}$ Neutral $\begin{gathered}\text { Agree } \\ \text { somewhat }\end{gathered}$ Agree $\begin{gathered}\text { Strongly } \\ \text { agree }\end{gathered}$}

_-_- 1. I am a worthy member of the J ewish people.

2. I often regret that I am a J ew.

3. Overall, being J ewish is considered good by others.

_--- 4. Overall, my J ewishness has very little to do with how I feel about myself.

_-_- 5. I feel I don't have much to offer to the J ewish people.

6. In general, I'm glad to be a J ew.

7. Most people consider the J ewish people, on the average, to be more ineffective than other groups.

8. Being a J ew, is an important reflection of who I am.

_-_- 9. I am a cooperative participant in the activities of the J ewish people.

_-_- 10. Overall, I often feel that the J ewish people are not worthwhile.

_-_ 11. In general, others respect my J ewishness.

12. My J ewishness is unimportant to my sense of what kind of a person I am.

_-_-_ 13. I often feel I'm a useless member of the J ewish people.

_-_- 14. I feel good about being part of the J ewish people.

15. In general, others think that the J ews are unworthy. image.

16. In general, belonging to the J ewish people is an important part of my self 


\section{Global Assessment of Spirituality - Revised Version}

Please indicate the extent to which you agree or disagree with each item below by using the following rating scale and filling in the appropriate circle on your answer sheet.
1
2
3
Strongly Disagree Disagree
Unsure
4
Agree
5

1. I know myself very well.

2. It distresses me to see other suffer even mild humiliation.

3. My closest relationships enhance my understanding of myself.

4. It is important to me that others be given the freedom to express their full potential as human beings.

5. I have had profound experiences that completely changed the way I think about life.

6. I regularly seek opportunities to learn more about myself.

7. I am part of something greater than myself.

8. I don't really think that much about what it is like for other people to lead their lives as they do.

9. I have had experiences of feeling "more alive" at certain times.

10. I often seek out opportunities to help others.

11. I don’t have enough energy to give fully to my relationships.

12. Even though there may be obstacles, I generally feel that path I am taking in my life is the right one.

13. It really disturbs me to see others being treated unfairly.

14. I feel as though I know myself better now than I used to.

15. I usually don't know how I’m feeling at a given moment.

16. There is more to reality than what can be experienced physically by the senses.

17. I sometimes experience an overwhelming sense of awe when I think about my connection to the universe.

18. I feel grounded in a reality that is beyond the physical.

19. I am not particularly interested in learning about cultures different from my own. 
20. I have more than one meaningful relationship from which I draw strength and comfort.

21. One of my main purposes in life is to be of service to others.

22. My life is part of a meaningful design for the universe.

23. I am willing to make personal sacrifices to see that those who cannot take care of themselves get their basic needs met.

24. I sometimes imagine what it would be like to see the world from another person's perspective.

25. I have had intense experiences of reality that I cannot explain.

26. I prefer to associate primarily with people who are as similar to me in background as possible.

27. I have experienced a deep sense of connection in conversation with others.

28. I feel most alive when I am giving of myself

29. I have never experienced a deep sense of peace for a sustained period of time.

30. Even when things are difficult, I know that I can make it.

31. I feel inspired to pursue the path that I am taking in my life.

32. I feel a deep connection to all living things.

33. Overcoming difficulties in my life has made me stronger.

34. I consider it my duty to take care of my family and friends.

35. I love myself.

36. I am curious about other people and what goes on in their lives.

37. I have had the experience of "losing myself" in engaging activities.

38. I draw strength from a source beyond myself in times of distress.

39. I have found my life's struggles to be deeply meaningful when I reflect on them.

40. I believe only what I can see for myself.

41. I reflect on my life and experiences quite often.

42. I find it easy to feel connected to other people. 
43. Part of my plan in life is to make a meaningful contribution to benefit others.

44. I am confident in my ability to face life’s challenges.

45. I have meaningful goals for my life.

46. When making important decisions, I consider what will make me the happiest personally.

47. I don't feel as though I have any special value or worth.

48. I like getting to know people who are very different from me.

49. My life extends beyond my bodily existence.

50. It is alright if other people don't understand or agree with me so long as I do what I believe is right.

51. More often than not, I approach life’s problems calmly.

52. I view death as an absolute end to life.

53. One of the things I value most in my relationships is freedom.

54. At a fundamental level, I feel connected even to people I do not know.

55. I don't tend to think about the needs of people outside my circle of friends and family.

56. I am often overwhelmed by the problems in my life.

57. When someone close to me has a great accomplishment, I am often as happy as I would be if it had happened to me.

58. The people around me don’t truly know who I am.

59. People who know me well would say that I am an open, accepting person.

60. I can sometimes step outside of my experiences to gain perspective.

61. Despite my current problems, I believe that ultimately I will be alright.

62. It is difficult for me to imagine the future being much better than right now

63. I feel peace and gratitude when I reflect on the good things in my life. 
64. There are certain activities during which I forget about myself and my thoughts.

65. I enjoy finding out new things about myself and other people.

66. I feel stuck where I am in my life. 


\section{Religious Orientation Scale}

Please indicate the extent to which you agree or disagree with each item below by using the following rating scale.

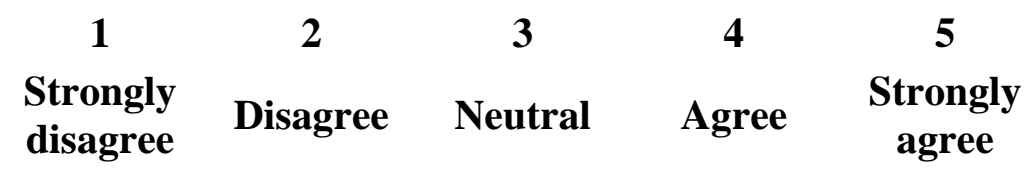

Intrinsic Subscale:

1. Although I believe in my religion, I feel there are many more important things in my life (R)

2. It is important for me to spend periods of time in private religious thought and meditation.

3. It doesn’t matter so much what I believe so long as I lead a moral life. (R)

4. I try hard to carry my religion over into all my other dealings in life.

5. Quite often I have been keenly aware of the presence of God or the Devine Being.

6. I read literature about my faith.

7. My religious beliefs are really what lie behind my whole approach to life.

8. Religion is especially important because it answers many questions about the meaning of life.

Extrinsic Subscale:

1. The primary purpose of prayer is to gain relief and protection.

2. My place of worship is most important as a place to formulate good social relationships.

3. What religion offers me most is comfort when sorrows and misfortune strike.

4. I pray chiefly because I have been taught to play.

5. A primary reason for my interest in religion is that my place of worship is a congenial social activity. 
6. Occasionally I find it necessary to compromise my religious beliefs in order to protect my social and economic well-being.

7. One reason for my being a synagogue member is that such membership helps to establish a person in the community.

8. The purpose of prayer is to secure a happy and peaceful life.

(R) = Reverse-scored item. 


\section{Center for Epidemiological Studies Depression Scale (CES-D)}

Instructions: Jam going to read a list of ways you may have felt. Please tell me how often you have felt this way during the past week: rarely or none of the time; some or a little of the time; occasionally or a moderate amount of time; or most or all of the time.

To total: Add all circled numbers in each column Total:

\begin{tabular}{|c|c|c|c|c|}
\hline $\begin{array}{l}\text { During the past week, that would be } \\
\text { from today: }\end{array}$ & $\begin{array}{l}\text { Rarely or } \\
\text { none } \\
\text { of the time } \\
\text { (less than } \\
1 \\
\text { day) }\end{array}$ & $\begin{array}{l}\text { Some or } \\
\text { a } \\
\text { little of } \\
\text { the } \\
\text { time } \\
\text { (1-2 } \\
\text { days) }\end{array}$ & $\begin{array}{l}\text { Occasionally } \\
\text { or } \\
\text { a Moderate } \\
\text { Amount of } \\
\text { Time } \\
\text { (3-4 days) }\end{array}$ & $\begin{array}{l}\text { Most or } \\
\text { all of } \\
\text { the time } \\
\text { (5-7 } \\
\text { days) }\end{array}$ \\
\hline $\begin{array}{l}\text { 1. You were bothered by things that } \\
\text { usually don't bother you. }\end{array}$ & 0 & 1 & 2 & 3 \\
\hline $\begin{array}{l}\text { 2. You did not feel like eating; your } \\
\text { appetite was poor. }\end{array}$ & 0 & 1 & 2 & 3 \\
\hline $\begin{array}{l}\text { 3. You felt that you could not shake off } \\
\text { the blues even with help from your } \\
\text { family or friends. }\end{array}$ & 0 & 1 & 2 & 3 \\
\hline $\begin{array}{l}\text { 4. You felt that you were just as good as } \\
\text { other people. }\end{array}$ & 3 & 2 & 1 & 0 \\
\hline $\begin{array}{l}\text { 5. You had trouble keeping your mind } \\
\text { on what you were doing. }\end{array}$ & 0 & 1 & 2 & 3 \\
\hline 6. You felt depressed. & 0 & 1 & 2 & 3 \\
\hline $\begin{array}{l}\text { 7. You felt that everything you did was } \\
\text { an effort. }\end{array}$ & 0 & 1 & 2 & 3 \\
\hline 8. You felt hopeful about the future. & 3 & 2 & 1 & 0 \\
\hline $\begin{array}{l}\text { 9. You thought your life had been a } \\
\text { failure. }\end{array}$ & 0 & 1 & 2 & 3 \\
\hline 10. You felt fearful. & 0 & 1 & 2 & 3 \\
\hline
\end{tabular}




\begin{tabular}{|l|l|l|l|l|}
\hline 11. Your sleep was restless. & 0 & 1 & 2 & 3 \\
\hline 12. You were happy. & 3 & 2 & 1 & 0 \\
\hline 13. You talked less than usual. & 0 & 1 & 2 & 3 \\
\hline 14. You felt lonely. & 0 & 1 & 2 & 3 \\
\hline 15. People were unfriendly. & 0 & 1 & 2 & 3 \\
\hline 16. You enjoyed life. & 3 & 2 & 1 & 0 \\
\hline 17. You had crying spells. & 0 & 1 & 2 & 3 \\
\hline 18. You felt sad. & 0 & 1 & 2 & 3 \\
\hline 19. You felt that people disliked you. & 0 & 1 & 2 & 3 \\
\hline 20. You could not get “going." & 0 & 1 & 2 & 3 \\
\hline
\end{tabular}


BELOW IS A LIST OF STATEMENTS DEALING WITH YOUR GENERAL FEELINGS ABOUT YOURSELF. IF YOU STRONGLY AGREE, CIRCLE SA. IF YOU AGREE WITH THE

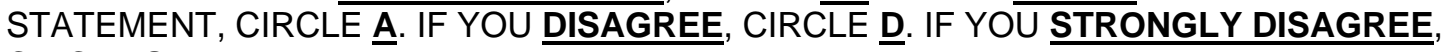
CIRCLE $\underline{\text { SD. }}$

\begin{tabular}{|c|c|c|c|c|c|}
\hline & & $\begin{array}{l}1 . \\
\text { Strongly } \\
\text { Agree }\end{array}$ & $\begin{array}{c}2 \\
\text { Agree }\end{array}$ & $\begin{array}{c}3 . \\
\text { Disagree }\end{array}$ & $\begin{array}{c}4 . \\
\text { Strongly } \\
\text { Disagree }\end{array}$ \\
\hline 1. & $\begin{array}{l}\text { I feel that I'm a person } \\
\text { of worth, at least on an } \\
\text { equal plane with others. }\end{array}$ & SA & A & D & SD \\
\hline 2. & $\begin{array}{l}\text { I feel that I have a } \\
\text { number of good } \\
\text { qualities. }\end{array}$ & SA & A & D & SD \\
\hline 3. & $\begin{array}{l}\text { All in all, I am inclined to } \\
\text { feel that I am a failure.** }\end{array}$ & SA & A & D & SD \\
\hline 4. & $\begin{array}{l}\text { I am able to do things as } \\
\text { well as most other } \\
\text { people. }\end{array}$ & SA & A & D & SD \\
\hline 5. & $\begin{array}{l}\text { I feel I do not have much } \\
\text { to be proud of.** }\end{array}$ & SA & A & D & SD \\
\hline 6. & $\begin{array}{l}\text { I take a positive attitude } \\
\text { toward myself. }\end{array}$ & SA & A & D & SD \\
\hline 7. & $\begin{array}{l}\text { On the whole, I am } \\
\text { satisfied with myself. }\end{array}$ & SA & A & D & SD \\
\hline 8. & $\begin{array}{l}\text { I wish I could have more } \\
\text { respect for myself.** }\end{array}$ & SA & A & D & SD \\
\hline 9. & $\begin{array}{l}\text { I certainly feel useless } \\
\text { at times.** }\end{array}$ & SA & A & D & SD \\
\hline 10. & $\begin{array}{l}\text { At times I think I am no } \\
\text { good at all.** }\end{array}$ & SA & A & D & SD \\
\hline
\end{tabular}




\section{Satisfaction with Life Scale}

Below are five statements with which you may agree or disagree. Using the 1-7 scale below, indicate your agreement with each item by placing the appropriate number on the line preceding that item. Please be open and honest in your responding.

$\begin{array}{ccccccc}1 & 2 & 3 & 4 & 5 & 6 & 7 \\ \begin{array}{c}\text { Strongly } \\ \text { disagree }\end{array} & \text { Disagree } & \begin{array}{c}\text { Disagree } \\ \text { somewhat }\end{array} & \text { Neutral } & \begin{array}{c}\text { Agree } \\ \text { somewhat }\end{array} & \text { Agree } & \begin{array}{c}\text { Strongly } \\ \text { agree }\end{array}\end{array}$

1. In most ways my life is close to my ideal

2. The conditions of my life are excellent.

3. I am satisfied with my life

4. So far I have gotten the important things I want in life.

5. If I could live my life over, I would change almost nothing. 


\section{Demographic Questionnaire}

1. What is your gender?
a. Female
b. Male

2. What is your age?

3. What is your race?
a. Asian
b. Black
c. White
d. Biracial
e. Multiracial
f. Other

4. What is your marital status?
a. Single
b. Married
c. Separated
d. Divorced
e. Cohabitating

5. What is the highest level of education that you have completed?
a. High school
b. College - first year
c. College - sophomore
d. College - junior
e. College - senior
f. Graduate student

6. What is your place of birth?
a. United States
b. Other

7. What is your employment status?
a. Employed - Full time
b. Employed - Part time
c. Unemployed
d. Student
e. Student and employed

8. What is your religious affiliation?
a. Orthodox
b. Conservative
c. Reform
d. Other
e. None

9. I consider myself to be a religious person.
a. True
b. False
c. Unsure

10. I consider myself to be a spiritual person.
a. True
b. False
c. Unsure 


\section{Prescreening Questionnaire}

Please indicate your responses to the questions below by circling the appropriate responses.

1. Do you consider yourself Jewish (either religiously, ethnically, or culturally)?
a. Yes
b. No
c. Unsure

2. Is your mother Jewish?
a. Yes
b. No
c. Don't know

3. Is your father Jewish?
a. Yes
b. No
c. Don't know

4. Did you have a Jewish upbringing?
a. Yes
b. No
c. Unsure

5. What is your place of birth?

a. United States

b. Other

\section{Contact Information:}

Name

Address

Phone number

Email 